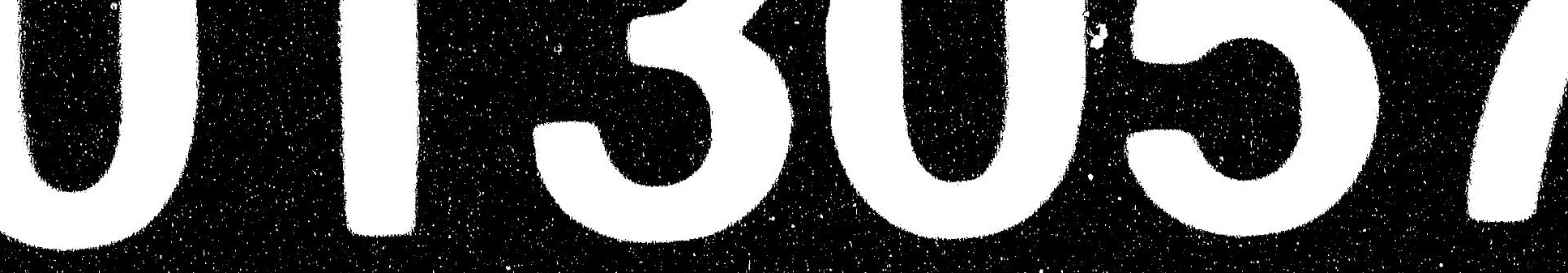




\title{
Vehicle/Guideway Interaction For High Speed Vehicles \\ On Flexible Guideway
}

\author{
Y. Cai, S. S. Chen, D. M. Rote and H. T. Coffey \\ Argonne National Laboratory \\ 9700 South Cass Avenue \\ Argonne, Illinois 60439 \\ ANL/CP- -74864
}

DE92 013057

\begin{abstract}
Dynamic interactions between vehicles and guideways of a high speed ground transportation system based on magnetically levitated vehicles are studied with an emphasis on the effects of vehicle and guideway parameters. Two dynamic models for vehicles are presented: first, the vehicle is considered as a moving force traveling on a simply-supported single-span or two-span beams with various speeds; and second, the vehicle is considered as a one dimensional model with two-degrees-of-freedom which represents the primary and secondary suspensions of a vehicle with lumped masses, linear springs, and dampings. The Bernoulli-Euler beam equation is used to model the characteristics of a flexible guideway, and the guideway synthesis is based on a modal analysis method. A series of analysis has been performed to understand the response characteristics under different loading conditions and provide some benchmark data for verifications of other comprehensive computer programs and some basic design guideline for maglev systems.
\end{abstract}




\section{Nomenclature}

C System damping Matrix

C Viscous damping coefficient of beam

$\mathrm{C}_{\mathrm{p}}$ Viscous damping coefficient for primary suspension of vehicle

$\mathrm{C}_{\mathrm{s}}$ Viscous damping coefficient for secondary suspension of vehicle

EI Bending rigidity of guideway structure

F Force applied on beam by vehicle

f Time varying force

$f_{n} \quad$ Natural frequencies of $n$-th mode

$f_{1}$ Natural frequency of fundamerital mode

g Gravitational acceleration

K System stiffness matrix

$\mathrm{k}_{\mathrm{n}}$ Eigenvalues of $\mathrm{n}$-th mode for a single-span beam vibration

$k_{p} \quad$ Stiffness for primary suspension of vehicle

$\mathrm{k}_{\mathrm{S}}$ Stiffness for secondary suspension of vehicle

L Span length of bearn

M System mass matrix

m Beam mass per unit length

$m_{p}$ Mass for primary suspension of vehicle

$\mathrm{m}_{\mathrm{S}}$ Mass for secondary suspension of vehicle

p System response vector

Q System force vector

$\mathrm{q}_{\mathrm{n}}$ Beam normal coordinates of $\mathrm{n}$-th mode

t Time

$u$ Displacement ratio of beam $\left(=w(x, t) /\left(p_{0} L^{3 / 48}\right)\right)$

v Vehicle velocity 
$\mathrm{v}_{\mathrm{c}}$ Critical vehicle velocity

$v_{n}$ Critical vehicle velocities of $n$-th mode

$\mathrm{v}_{\mathrm{r}} \quad$ Velocity ratio

$v_{1}$ Critical vehicle velocity of fundamental mode

w Total displacement of beam

$\mathrm{x}$ Axial coordinate of beam

Y Dimensionless displacement of beam

y Displacement of beam

$\mathrm{y}_{\mathrm{m}}$ Midspan displacement of beam

$\mathrm{Y}_{\mathrm{O}}$ Dimensionless perturbation on beam

$\mathrm{y}_{0} \quad$ Perturbation on beam

$Y_{p}$ Dimensionless displacement of primary suspension of vehicle

$y_{p} \quad$ Displacement of primary suspension of vehicle

$\mathrm{Y}_{\mathrm{S}}$ Dimensionless displacement of secondary suspension of vehicle

$y_{s}$ Displacement of secondary suspension of vehicle

$\alpha_{n}$ Dimensionless beam normal coordinates of $n$-th mode

$\gamma_{f}$ Frequency ratio of secondary to primary suspension

$\gamma_{\mathrm{m}}$ Mass ratio of primary to secondary suspension

$\Delta \quad$ Function defined in Eq. 36

$\delta \quad$ Function defined in Eq. 22

$\zeta_{n}$ Modal damping rations of $n$-th mode for beam

$\zeta_{p}$ Modal damping ration of for primary suspension of vehicle

$\zeta_{\mathrm{s}}$ Modal damping ration of for secondary suspension of vehicle

$\varepsilon \quad$ Mass ratio of vehicle to guideway

$\varepsilon_{\mathrm{p}}$ Mass ratio of vehicle primary suspension to guideway

$\varepsilon_{\mathrm{S}} \quad$ Mass ratio of vehicle secondary suspension to guideway

$\lambda_{n} \quad$ Beam eigenvalues of $n$-th mode 
$\xi \quad$ Dimensionless axial coordinate

$\xi_{\mathrm{v}}$ Location of moving force on beam when maximum beam displacement $\operatorname{occurs}(=v t / \mathrm{L})$

Location of vehicle on beam when maximum beam displacement occurs $\left(=\mathrm{v}_{\mathrm{r}} \tau / \pi\right)$

$\tau \quad$ Dimensionless time

$\phi_{\mathrm{n}}$ Orthonormal function of $\mathrm{n}$-th mode

$\Omega$ Oscillating frequency of a moving force on beam,

Frequency ratio of vehicle to guideway

$\omega$ Crossing frequency

$\omega_{\mathrm{n}}$ Normal frequencies of $n$-th mode

$\omega_{\mathrm{p}}$ Uncoupling natural frequency of primary suspension

$\omega_{\mathrm{S}}$ Uncoupling natural frequency of secondary suspension

\section{Subscripts}
n n-th mode
p For primary suspension
s For secondary suspension
1 For fundamental mode 


\section{Introduction}

A high speed ground transportation system based on magnetically levitated vehicles that are propelled with a linear electric motor has been proposed to meet future intercity transportation requirements. One possible and attractive approach is to replace air travel for intercity flights of between 100 and 600 miles on selected routes. The maglev systems will not only offer the advantages of less noise and emissions and better ride quality, but also potential energy savings and economics benefits. ${ }^{[6,7,16]}$

For several decades, research and development has been performed in the areas of magnetic levitation, response of maglev vehicles to rough guideways, interaction of variously suspended vehicles with flexible guideways and optimization of vehicle suspensions. Those results are useful in providing appropriate criteria in the design of maglev systems. ${ }^{11,7,11]}$ More emphasis should be placed on guideway design because the cost of the guideway structure of a maglev line is expected to be about 60 to 80 percent of the initial capital investment for different maglev systems. ${ }^{[13,16]}$ The guideway design is a critical area which may result in potential capital savings. An optimized design of guideways will be important for a maglev system at high speed with good ride quality. As vehicle speeds of maglev system increase to the $200-300 \mathrm{mph}$ range or as guideways become lighter and more flexible in order to reduce costs, the dynamic interactions between vehicles and guideways become an important problem and will play a dominant role in establishing vehicle suspension requirements and guideway stiffness, weight, and span-length specifications. ${ }^{[1,16]}$

The purpose of this paper is to discuss the problems associated with modelling vehicle/guideway interactions and to understand the response characteristics under different loading conditions. This study will also provide some benchmark data for verification of other comprehensive computer programs and some basic design guideline for maglev systems. Of particular interest are the effects of variations in the fundamental vehicle and guideway parameters that 
relate to the dynamic interaction. A series of analyses has been performed for simplified models to provide basic information; they are intended to answer various questions. For example, (1) Under what conditions can we neglect the dynamic coupling of vehicles and guideways for EDS and EMS systems? (2) What models of the vehicles and guideways should be used in the analysis for different maglev systems?

This study includes two dynamic models for vehicles: first, the vehicle is considered as a moving force traveling on a simply-supported single-span or twospan beams with various speeds; and second, the vehicle is considered as a one dimensional model with two-degrees-of-freedom which represents the primury and secondary suspensions of a vehicle with lumped masses, linear springs, and dampings. In these simplified vehicle models, only the vertical motion of the vehicle is corsidered. This is based on the assumption that the vertical motion is dominant and other inotions can be ignored when the vertical motion is evaluated. For a flexible guideway, the elastic deformation of the guideway has to be considered. Therefore, the Bernoulli-Euler beam equation is used to model the guideway characteristics. In above cases the guideway synthesis is based on a modal analysis method; both closed form and numerical solutions are applied to solve the equations of motion for vehicle/guideway interaction. The results show that a numerical solution with time integration has the same accuracy as the closed form solution.

\section{Vehicle as a Moving Force on Guideway}

When the coupling of vehicle and guideway is ignored, a vehicle may be described as a moving force traveling on a flexible guideway. Two cases of guideways are considered: a single-span beam and two-span beam. Extensive studies have been published on moving loads acting on elastic structures. $[5,8,12,14]$ This study is to emphasize applications to maglev systems. 


\subsection{A Moving Force on a Single-Span Beam}

As shown in Fig. 1, a simply-supported single-span beam is subjected to a force moving with speed $v$. The equation of motion is given by

$$
E I \frac{\partial^{4} w}{\partial x^{4}}+C \frac{\partial w}{\partial t}+m \frac{\partial^{2} w}{\partial t^{2}}=p \delta(x-v t)
$$

where $w$ is the beam deflection, $x$ is the axial coordinate of the beam, $t$ is time, $m$ is the beam mass per unit length, EI is the flexural rigidity, $\mathrm{C}$ is the viscous damping coefficient, and the moving force $p$ consists of a steady component $p_{0}$ and a pulsating component $\mathrm{p}_{1} \sin \Omega$ t. The boundary conditions are

$$
\begin{aligned}
& w(0, t)=0 ; \quad w(L, t)=0 ; \\
& \frac{\partial^{2} w}{\partial x^{2}}(0, t)=0 ; \quad \frac{\partial^{2} w(L, t)}{\partial x^{2}}=0 ;
\end{aligned}
$$

and the initial conditions are

$$
\begin{aligned}
& w(x, 0)=0 \\
& \frac{\partial w}{\partial t}(x, 0)=0 .
\end{aligned}
$$

The mathematical problem specified by Eqs. 1, 2 and 3 can easily be solved using the modal analysis method. The results are summarized as follows:

$$
w(x, t)=\sum_{n=1}^{\infty} q_{n}(t) \phi_{n}(x) .
$$

where 


$$
\phi_{n_{1}}(x)=\sqrt{2} L \sin \left(\frac{n \pi x}{L}\right)
$$

and $\mathrm{q}_{\mathrm{n}}(\mathrm{t})$ is the solution of the following equation,

$$
\begin{aligned}
& \frac{\mathrm{d}^{2} \mathrm{q}_{\mathrm{n}}}{d \mathrm{t}^{2}}+2 \zeta_{\mathrm{n}} \omega_{\mathrm{n}} \frac{\mathrm{dq}}{\mathrm{dt}}+\omega_{\mathrm{n}}^{2} \mathrm{q}_{\mathrm{n}}=\frac{\sqrt{2}}{\mathrm{~L}^{2} \mathrm{~m}}\left(\mathrm{p}_{0}+\mathrm{p}_{1} \sin \Omega \mathrm{t}\right) \sin (\mathrm{n} \omega \mathrm{t}), \\
& \omega_{\mathrm{n}}=\frac{\mathrm{n}^{2} \pi^{2}}{\mathrm{~L}^{2}} \sqrt{\frac{\mathrm{EI}}{\mathrm{m}}} \\
& \zeta_{\mathrm{n}}=\frac{\mathrm{C}}{2 \mathrm{~m} \omega_{\mathrm{n}}} \\
& \omega=\frac{\pi \mathrm{v}}{\mathrm{L}} .
\end{aligned}
$$

Note that $\omega_{n}$ is the natural frequency (in radian) of the $n$-th mode, $\zeta_{n}$ is the corresponding modal damping ratio, and $\omega$ is the crossing frequency (in radian).

From Eq. 6, several interesting features are noted:

(1) When $\omega_{\mathrm{n}}=\mathrm{n} \omega$,

$$
\mathrm{v}_{\mathrm{n}}=\frac{\mathrm{n} \pi}{\mathrm{L}} \cdot \sqrt{\frac{\mathrm{EI}}{\mathrm{m}}}
$$

or

$$
v_{n}=\frac{2 f_{n} L}{n}, \quad f_{n}=\frac{2 \pi}{\omega_{n}}
$$

where $v_{n}$ is the critical speed of the $n$-th mode. The first critical speed is $v_{1}\left(=\frac{\pi}{L} \sqrt{\frac{E I}{m}}=2 f_{1} L\right)$. When $v=v_{1}$, the crossing frequency is equal to twice the natural frequency of the fundamental mode. 
(2) When $\omega_{n}=\frac{\Omega \pm n \omega}{2}$, the pulsating force is in resonance with the beam.

The displacement of the beam can be calculated easily from Eqs. 4-6. To make the results easily understood, all beam displacements will be expressed as the ratio of the beam displacement to the static deflection at $\mathrm{x}=\mathrm{L} / 2$ due to $\mathrm{p}_{\mathrm{o}}$ at $\mathrm{x}=$ $\mathrm{L} / 2$; this deflection is equal to $\mathrm{p}_{0} \mathrm{~L} 3 / 48 \mathrm{EI}$. The displacement ratio is denoted by $u(x / L)$, which is a function of the following parameters, $v / v_{1}, \zeta_{n}$, and $x / L$.

Equation 4 can be used to calculate the beam displacement at any location and at any time as a function of damping, $\zeta_{n}$, and velocity ratio $\mathrm{v} / \mathrm{v}_{1}$. The maximum displacement is of particular interest because it is related to the stresses in the beam and vehicle response. The maximum displacement ratio, $u_{\max }$, was found to occur at $x / L=0.5$ for a single-span beam. The maximum displacement ratio and the location of the moving force when the maximum displacement develops as a function of velocity ratio v/v1 are given in Fig. 2 for the single-span beam. From Fig. 2, the maximum displacement ratio is about 1.7 for $\zeta_{n}=2 \%$ when $v / v_{1}$ is about 0.6 . As the damping is increased to $10 \%$, the maximum displacement ratio is reduced to about 1.52 . When the velocity ratio is larger than 1.5 for $\zeta_{n}=10 \%$ and 1.75 for $\zeta_{n}=2 \%$, the displacement ratio is smaller than 1. For $\mathrm{v} / \mathrm{v}_{1}$ smaller than 0.5 , the maximum displacement develops when the moving force is close to the midspan. As v/vi increases, the location of the moving force, $\mathrm{x} / \mathrm{L}$, increases with $\mathrm{v} / \mathrm{v}_{1}$.

Since the maximum displacement is at $\mathrm{x} / \mathrm{L}=0.5$ on the single-span beam, the time history of displacement ratio at $\mathrm{x} / \mathrm{L}=0.5$ as a function of the location of the moving force $\mathrm{p}_{0}$ is shown in Fig. 3 for various values of $v / v_{1}$. In Fig. 3 , the location $\xi_{\mathrm{v}}=\mathrm{vt} / \mathrm{L}=0$ to 1 means the moving force on the first beam and $\xi_{v}=1$ to 2 means the moving force on the next beam. Some characteristics are noted. For very small value of $v / v_{1}$, the response is very close to the static load ( $v / v_{1}=0.0$ ); for $0.5<\mathrm{v} / \mathrm{v}_{1}<1.0$, the maximum response occurs when the load $\mathrm{p}_{0}$ has already passed the midspan; and for $v / v_{1}>1$, the maximum response occurs after $p_{0}$ has 
left the beam to the next beam. Increasing damping tends to decrease beam response regarilless of the value of $v^{\prime} / v_{1}$.

Figure 4 shows the displacement ratio at the midspan due to a moving force with a steady component $p_{0}$ and pulsating component $p_{1}\left(=0.1 p_{0}\right)$ for two values of the velocity $r$ tio and several frequency ratios $\Omega / \omega_{1}$. When $\Omega=\omega_{1}$, as shown in Fig. 4a, the palsating component is in resonance with the fundamental natural frequency and its response increases significantly. Once the moving force leaves the span, its $r$ əsponse will start to decrease.

\subsection{A Moving Force on a Two-Span Beam}

Figure 5 shows a beam with two equal spans subjected to a moving force $p$. The general nethod of solution is similar to that for a single-span beam. The results are summarized as follows:

$$
\begin{aligned}
& w(x, t)=\sum_{i=1}^{\infty} q_{n}(t) \phi_{n}(x), \\
& x=0 \text { to } 2 L .
\end{aligned}
$$

The mode shapes are given as follows:

(1) $\mathrm{n}=1,3,5,7,9, \ldots$

$$
\phi_{\mathrm{n}}(\mathrm{x})=\sin \left[\frac{(\mathrm{n}+1) \pi}{2} \frac{\mathrm{x}}{\mathrm{L}}\right]
$$

(2) $\mathrm{n}=2,4,6,8,10, \ldots$

$$
0 \leq \mathrm{x} \leq \mathrm{L} \text {, }
$$




$$
\phi_{\mathrm{n}}(\mathrm{x})=\sin \frac{\mathrm{k}_{\mathrm{n}} \mathrm{x}}{\mathrm{L}}-\frac{\sin \mathrm{k}_{\mathrm{n}}}{\sinh \mathrm{k}_{\mathrm{n}}} \sinh \frac{k_{\mathrm{n}} \mathrm{x}}{\mathrm{L}}
$$

$\mathrm{L} \leq \mathrm{x} \leq 2 \mathrm{~L}$

$$
\phi_{\mathrm{n}}(\mathrm{x})=\sin \mathrm{k}_{\mathrm{n}}\left(\frac{2 \mathrm{~L}-\mathrm{x}}{\mathrm{L}}\right)-\frac{\sin \mathrm{k}_{\mathrm{n}}}{\sinh \mathrm{k}_{\mathrm{n}}} \sinh \mathrm{k}_{\mathrm{n}}\left(\frac{2 \mathrm{~L}-\mathrm{x}}{\mathrm{L}}\right)
$$

where $k_{n}$ is the solution of the characteristic equation,

$$
\tan k_{n}=\tanh k_{n}
$$

The values of $\mathrm{k}_{\mathrm{n}}$ obtained from Eq. 11 are $3.39,7.07,10.21,13.35, \ldots$.

$q_{n}(t)$ is calculated from the following equations

(1) $\mathrm{n}=1,3,5,7, \ldots$

$$
\frac{d^{2} q_{n}}{d t^{2}}+2 \zeta_{n} \omega_{n} \frac{d q_{n}}{d t}+\omega_{n}^{2} q_{n}=\left(p_{0}+p_{1} \sin \Omega t\right) \sin (n \omega t)
$$

(2) $\mathrm{n}=2,4,6,8, \ldots$

a. $\quad 0 \leq \mathrm{vt} \leq \mathrm{L}$

$$
\begin{aligned}
\frac{d^{2} q_{n}}{d t^{2}} & +2 \zeta_{n} \omega_{11} \frac{d q_{n}}{d t}+\omega_{n}^{2} q_{n} \\
= & \left(p_{0}+p_{1} \sin \Omega_{2 t}\right)\left[\sin \left(k_{n} v t\right)-\frac{\sin k_{n}}{\sinh k_{n}} \sinh \left(k_{n} v t\right)\right]
\end{aligned}
$$

b. $\mathrm{L} \leq \mathrm{vt} \leq 2 \mathrm{~L}$ 


$$
\begin{aligned}
\frac{d^{2} q}{d t^{2}} & =2 \zeta_{n} \omega_{n} \frac{d q_{n}}{d t}+\omega_{n}^{2} q_{n} \\
& =\left(p_{0}+p_{1} \sin \Omega t\right)\left[\sin k_{n}(2-v t)-\frac{\sin k_{n}}{\sinh k_{n}} \sinh k_{n}(2-v t)\right]
\end{aligned}
$$

Th 3 natural frequencies $\omega_{n}$ given in Eqs. 12, 13, and 14 are given by

$$
\begin{aligned}
& \omega_{\mathrm{n}}=\frac{\lambda_{\mathrm{n}}^{2}}{\mathrm{~L}^{2}} \sqrt{\frac{\mathrm{EI}}{\mathrm{m}}} \\
& \zeta_{\mathrm{n}}=\frac{\mathrm{C}}{2 \mathrm{~m} \omega_{\mathrm{n}}} \\
& \omega=\frac{\pi \mathrm{v}}{\mathrm{L}}
\end{aligned}
$$

where

$$
\begin{aligned}
\lambda_{\mathrm{n}} & =\frac{(\mathrm{n}+1) \pi}{2}, & \mathrm{n}=1,3,5,7, \ldots \\
& =\mathrm{k}_{\mathrm{n}}, & \mathrm{n}=2,4,6,8, \ldots
\end{aligned}
$$

For a two-span beam, the maximum displacement ratio defined in the same way as a single-span beam was found to occur at $x / L=0.5$ or 1.5 . The maximum displacement ratio and the location of the moving force when the maximum displacement develops and their comparisons with a single-span beam are shown in Fig. 6. Figure 7 shows the time history of displacement ratio at $x / L=0.5$ and 1.5 for a series $v / v_{1}$ of when the force $p_{0}$ is at various locations.

The response characteristics at $\mathrm{x} / \mathrm{L}=0.5$ are similar to those of a single-span beam except that the maximum displacement ratio is smaller. The displacement ratio at $\mathrm{x} / \mathrm{L}=1.5$ changes significantly with $\mathrm{v} / \mathrm{v}_{1}$. When $\mathrm{v} / \mathrm{v}_{1}$ is between 0.65 to 1.4 , the displacement ratio is larger than those of a single-span beam. When the 
maximum displacement occurs at $\mathrm{x} / \mathrm{L}=1.5$, the location of moving force is close to $\mathrm{x} / \mathrm{L}=1.5 \mathrm{when} \mathrm{v}_{\mathrm{v}} / \mathrm{v}_{1}$ is smaller than about 0.6 and then increases with $\mathrm{v} / \mathrm{v}_{1}$.

For maglev systems, the velocity ratio, $v / v_{1}$, is expected to be not larger than 0.5. In this situation, the maximum displacement ratio for a two-span beam is smaller than that for a single-span beam. Without considering other factors, a two-span beam appears to be more efficient in achieving better ride quality.

\section{A Two-Degree-of-Freedom Vehicle on a Flexibls Guideway}

\subsection{Equation of Motion}

A one-dimensional vehicle model with two-degree-of-freedom traveling on a simply supported gilideway is shown in Fig. 8. The vehicle model consists of two lumped masses, $m_{p}$ and $m_{s}$, two linear springs, $k_{p}$ and $k_{s}$, and two viscous dampings, $C_{p}$ and $C_{s}$, represented for primary and secondary suspensions respectively. The guideway is considered as a Bernoulli-Euler beam of uniform cross-section. The displacement $w(x, t)$ of the beam consists of initial irregularities $\mathrm{y}_{0}(\mathrm{x})$ and deformation $\mathrm{y}(\mathrm{x}, \mathrm{t})$ which is caused by the vehicle and measured positive downwards,

$$
w(x, t)=y_{0}(x)+y(x, t)
$$

The displacement of two masses $m_{p}$ and $m_{s}$ are $y_{p}$ and $y_{s}$, which are measured positive upwards from their static equilibrium positions. Then equations of motion for the vehicle are

$$
\begin{aligned}
& m_{p} \frac{d^{2} y_{p}}{d t^{2}}+m_{s} \frac{d^{2} y_{s}}{d t^{2}}+C_{p}\left(\frac{d y_{p}}{d t}+\frac{d w}{d t}\right)+k_{p}\left(y_{p}+w\right)=-\left(m_{p}+m_{s}\right) g, \\
& m_{s} \frac{d^{2} y_{p}}{d t^{2}}+C_{s}\left(\frac{d y_{s}}{d t}-\frac{d y_{p}}{d t}\right)+k_{s}\left(y_{s}-y_{p}\right)=-m_{s} g
\end{aligned}
$$


where $t$ is time. When vehicle is traveling at a constant velocity $v$, the force $F(x, t)$ applied to the beam by the vehicle may be expressed as

$$
\begin{aligned}
& F(x, t)=f(t) \delta(x-v t) \\
& f(t)=\left(m_{p}+m_{s}\right) g+\left(m_{p} \frac{d^{2} y_{p}}{d t^{2}}+m_{s} \frac{d^{2} y_{S}}{d t^{2}}\right)
\end{aligned}
$$

where

$$
\delta= \begin{cases}1 & 0 \leq x(=v t) \leq L \\ 0 & x(=v t)>L\end{cases}
$$

Then, the equation of motion of the beam is

$$
E I \frac{\partial^{4} y}{\partial x^{4}}+C \frac{\partial y}{\partial t}+m \frac{\partial^{2} y}{\partial t^{2}}=F(x, t)
$$

where $\mathrm{x}$ is the axial coordinate of the beam, EI is the bending rigidity of the beam, $\mathrm{C}$ is the viscous damping coefficient, and $\mathrm{m}$ is the beam mass per unit length. The boundary condition of the beam are

$$
\begin{aligned}
& y(t, 0)=\frac{\partial^{2} y(t, 0)}{\partial x^{2}}=0, \\
& y(t, 1)=\frac{\partial^{2} y(t, L)}{\partial x^{2}}=0 .
\end{aligned}
$$

In the modal analysis method, the displacement of the bean is expressed in terms of orthonormal modes $\varphi_{n}(x)$ : 


$$
\begin{aligned}
& \varphi_{n}(x)=\sqrt{2} \sin \left(\frac{n \pi x}{L}\right), \\
& y(x, t)=\sum_{n=1}^{\infty} q_{n}(t) \varphi_{n}(x) .
\end{aligned}
$$

$q_{n}(t)$ is the solution of the equation

$$
\frac{\mathrm{d}^{2} \mathrm{q}_{\mathrm{n}}}{\mathrm{dt^{2 }}}+2 \zeta_{n} \omega_{\mathrm{n}} \frac{\mathrm{dq} \mathrm{q}_{\mathrm{n}}}{\mathrm{dt}}+\omega_{\mathrm{n}} q_{\mathrm{n}}=\frac{1}{\mathrm{Lm}} \int_{0}^{L} \mathrm{~F}(\mathrm{x}, \mathrm{t}) \varphi_{\mathrm{n}}(\mathrm{x}) \mathrm{dx}
$$

where $\omega_{\mathrm{n}}$ and $\zeta_{\mathrm{n}}$ are the circular frequency and modal damping ratio of the beam and given by

$$
\begin{aligned}
& \omega_{\mathrm{n}}=\frac{\lambda_{\mathrm{n}}^{2}}{\mathrm{~L}^{2}} \sqrt{\frac{\mathrm{EI}}{\mathrm{m}}}, \\
& \zeta_{\mathrm{n}}=\frac{\mathrm{C}}{2 \mathrm{~m} \omega_{\mathrm{n}}} .
\end{aligned}
$$

For a single-span beam, $\lambda_{n}=2 n \pi, n=1,2,3, \ldots$.

When a concentrated load, $\left(m_{p}+m_{s}\right) g$, is placed at the midspan, the midspan displacement associated with the fundamental mode can be derived from Equation 27,

$$
q_{1}=\frac{\sqrt{2}\left(m_{p}+m_{s}\right) g}{m L \omega_{1}^{2}}
$$

Therefore, the midspan displacement $y_{m}$, is

$$
\mathrm{y}_{\mathrm{m}}=\mathrm{q}_{1} \varphi_{1}\left(\frac{\mathrm{L}}{2}\right)=\frac{2\left(\mathrm{~m}_{\mathrm{p}}+\mathrm{m}_{\mathrm{s}}\right) \mathrm{g}}{\mathrm{mL} \omega_{1}^{2}}
$$


Uncoupled natural frequencies and modal damping ratios are defined as follow:

$$
\begin{aligned}
& \omega_{p}=\sqrt{\frac{k_{p}}{m_{p}+m_{s}}}, \\
& \omega_{s}=\sqrt{\frac{k_{s}}{m_{s}}}, \\
& \zeta_{p}=-\frac{C_{p}}{2\left(m_{p}+m_{s}\right) \omega_{p}}, \\
& \zeta_{s}=\frac{C_{s}}{2 m_{s} \omega_{s}} .
\end{aligned}
$$

Several nondimensional parameters are introduced:

$$
\begin{aligned}
& \varepsilon=\frac{m_{p}+m_{s}}{m L}, \quad \varepsilon_{p}=\frac{m_{p}}{m L}, \quad \varepsilon_{s}=\frac{m_{s}}{m L}, \\
& \gamma_{m}=\frac{m_{p}}{m_{s}}, \\
& \Omega=\frac{\omega_{1}}{\omega_{p}}, \\
& \gamma_{f}=\frac{\omega_{s}}{\omega_{p}}, \\
& Y_{p}=\frac{y_{p}}{y_{r n}}, \quad Y_{s}=\frac{y_{s}}{y_{m}}, \quad Y_{0}=\frac{y_{0}}{y_{m}}, \quad Y=\frac{y}{y_{m}}, \\
& \xi=x / L,
\end{aligned}
$$




$$
\begin{aligned}
& \alpha_{n}=\frac{q_{n}}{y_{m}}, \\
& \tau=\omega_{1} t, \\
& v_{r}=\frac{\pi v}{L \omega_{1}}=\frac{v}{v_{1}}=\frac{v}{v_{c}} \quad\left(v_{c}=2 f_{1} L\right), \\
& \xi_{v}=\frac{v t}{L}=\frac{v_{r} \tau}{\pi} .
\end{aligned}
$$

These parameters are considered based on the published data related to maglev systems. $[2-4,6,9,10]$

$v_{r}$ is ratio of vehicle speed to critical speed $v_{c}$. The critical speed $v_{c}$ is equal to $2 f_{1} L\left(f_{1}=\omega_{1} / 2 \pi\right) . \varepsilon, \varepsilon_{p}$ and $\varepsilon_{s}$ a ${ }^{\prime} e$ mass ratios of vehicle components to the guideway. $\gamma_{\mathrm{m}}$ is mass ratio of primary suspezsion to secondary suspension. Those ratios vary considerably. In general, $0.1 \leq \varepsilon \leq 1.0$, and $\varepsilon_{\mathrm{S}}$ is much larger than $\varepsilon_{\mathrm{p}} . \gamma_{\mathrm{m}}$ ranges from 0.05 to 0.20 .

$\Omega$ is ratio of the fundamental frequency of the guideway to the frequency of vehicle primary suspension system, typically, this ratio is between 1 to 10 .

$\gamma_{\mathrm{f}}$ is ratio of uncoupled frequencies of primary to secondary suspensions. This ratio depends on the ratios of $k_{p} / k_{s}$ and $\left(m_{p}+m_{s}\right) / m_{s}$. It ranges from 0.04 to 0.25 .

$\zeta_{\mathrm{p}}, \zeta_{\mathrm{s}}$ and $\zeta_{\mathrm{n}}$ are damping ratios of vehicle and guideway. The guideway damping ratio $\zeta_{n}$ is generally small; its value is about $1 \%$ to $5 \%$ depending on the span length. In general, it is $1 \%$ or $2 \%$. The vehicle damping ratios $\zeta_{\mathrm{p}}$ and $\zeta_{\mathrm{s}}$ depend on different designs. In our study, $\zeta_{\mathrm{p}}$ ranges from 0.05 to 0.50 and $\zeta_{\mathrm{s}}$ ranges from 0.1 to 0.25 .

Using Eqs. 17, 31, and 32, Eqs. 18, 19 and 27 can be rewritten as 


$$
\begin{aligned}
& \Omega^{2} \ddot{Y}_{p}+\frac{\varepsilon_{s}}{\varepsilon_{p}} \Omega^{2} \ddot{Y}_{s}+2 \zeta_{p} \Omega\left(\dot{Y}_{p}+\dot{Y}\right)+\frac{\varepsilon}{\varepsilon_{p}}\left(Y_{p}+Y\right)=-\frac{\Omega^{2}}{2 \varepsilon_{p}}-2 \zeta_{p} \Omega \dot{Y}_{0}\left(\xi_{v}\right)-\frac{\varepsilon}{\varepsilon_{p}} Y_{0}\left(\xi_{v}\right) \\
& \Omega^{2} \ddot{Y}_{s}+2 \zeta_{s} \Omega \gamma_{f}\left(\dot{Y}_{s}-\dot{Y}_{p}\right)+\gamma_{f}^{2}\left(Y_{s}-Y_{p}\right)=-\frac{\Omega^{2}}{2 \varepsilon} \\
& \ddot{\alpha}_{n}+2 \zeta_{n} \frac{\omega_{n}}{\omega_{1}} \dot{\alpha}_{n}+\left(\frac{\omega_{n}}{\omega_{1}}\right)^{2} \alpha_{n}=\Delta\left(\frac{1}{2}+\varepsilon_{p} \ddot{Y}_{p}+\varepsilon_{s} \ddot{Y}_{s}\right) \varphi_{n}\left(\xi_{v}\right)
\end{aligned}
$$

where

$$
\begin{aligned}
& \Delta= \begin{cases}1 & 0 \leq \xi_{\mathrm{v}} \leq 1 \\
0 & \xi_{\mathrm{v}}>1\end{cases} \\
& \varphi_{\mathrm{n}}\left(\xi_{\mathrm{v}}\right)=\sqrt{2} \sin \left(\lambda_{\mathrm{n}} \mathrm{r}_{\mathrm{v}}\right), \\
& \left.\quad=\sqrt{2} \sin \left(\mathrm{n} \mathrm{v}_{\mathrm{r}} \mathrm{z}\right), \quad \text { (for a single }- \text { span beam }\right)
\end{aligned}
$$

and

$$
Y(\xi, \tau)=\sum_{n=1}^{\infty} \alpha_{n}(\tau) \varphi_{n}(\xi)
$$

Equations 33 and 35 are coupled second order ordinary differential equations with constant coefficient. The number of normal coordinates in the beam equation goes to infinity, but significant contributions come from a few natural modes. Let this number be $n$. The system equations 33 to 35 can be represented in matrix form by a $N(=2+n)$ size set:[15]

$$
M \ddot{p}+C \dot{p}+K p=Q
$$


where

$M=\left[\begin{array}{ccccc}\Omega^{2} & \frac{\varepsilon_{\mathrm{s}}}{\varepsilon_{\mathrm{p}}} \Omega^{2} & 0 & 0 & \ldots \\ 0 & \Omega^{2} & 0 & 0 & \ldots \\ -\Delta \varepsilon_{\mathrm{p}} \varphi_{1}\left(\xi_{\mathrm{v}}\right) & -\Delta \varepsilon_{\mathrm{s}} \varphi_{1}\left(\xi_{\mathrm{v}}\right) & 1 & 0 & \ldots \\ -\Delta \varepsilon_{\mathrm{p}} \varphi_{2}\left(\xi_{\mathrm{v}}\right) & -\Delta \varepsilon_{\mathrm{s}} \varphi_{2}\left(\xi_{\mathrm{v}}\right) & 0 & 1 & \ldots \\ \vdots & \vdots & \vdots & \vdots & \vdots\end{array}\right]$

$\mathrm{C}=\left[\begin{array}{ccccc}2 \zeta_{\mathrm{p}} \Omega & 0 & 2 \zeta_{\mathrm{p}} \Omega \varphi_{1}\left(\xi_{\mathrm{v}}\right) & 2 \zeta_{\mathrm{p}} \Omega \varphi_{2}\left(\xi_{\mathrm{v}}\right) & \ldots \\ -2 \zeta_{\mathrm{s}} \Omega \gamma_{\mathrm{f}} & 2 \zeta_{\mathrm{s}} \Omega \gamma_{\mathrm{f}} & 0 & 0 & \ldots \\ 0 & 0 & 2 \zeta_{\mathrm{n}}\left(\frac{\omega_{1}}{\omega_{1}}\right) & 0 & \ldots \\ 0 & 0 & 0 & 2 \zeta_{\mathrm{n}}\left(\frac{\omega_{2}}{\omega_{1}}\right) & \ldots \\ \vdots & \vdots & \vdots & \vdots & \vdots\end{array}\right]$

$$
\mathrm{K}=\left[\begin{array}{ccccc}
\frac{\varepsilon}{\varepsilon_{\mathrm{p}}} & 0 & \frac{\varepsilon}{\varepsilon_{\mathrm{p}}} \varphi_{1}\left(\xi_{\mathrm{v}}\right) & \frac{\varepsilon}{\varepsilon_{\mathrm{p}}} \varphi_{2}\left(\xi_{\mathrm{v}}\right) & \ldots \\
-\gamma_{\mathrm{f}}^{2} & \gamma_{\mathrm{f}}^{2} & 0 & 0 & \ldots \\
0 & 0 & \left(\frac{\omega_{1}}{\omega_{1}}\right)^{2} & 0 & \ldots \\
0 & 0 & 0 & \left(\frac{\omega_{2}}{\omega_{1}}\right)^{2} & \ldots \\
\vdots & \vdots & \vdots & \vdots & \vdots
\end{array}\right]
$$




$$
Q=\left[\begin{array}{c}
-\frac{\Omega^{2}}{2 \varepsilon_{p}}-2 \zeta_{p} \Omega \dot{Y}_{0}\left(\xi_{v}\right)-\frac{\varepsilon}{\varepsilon_{p}} Y_{0}\left(\xi_{v}\right) \\
-\frac{\Omega^{2}}{2 \varepsilon} \\
\frac{\Delta}{2} \varphi_{1}\left(\xi_{v}\right) \\
\frac{\Delta}{2} \varphi_{\eta}\left(\xi_{v}\right) \\
\vdots
\end{array}\right], \quad p=\left[\begin{array}{c}
Y_{p} \\
Y_{s} \\
\alpha_{1} \\
\alpha_{2} \\
\vdots
\end{array}\right]
$$

$\mathrm{M}, \mathrm{C}$ and $\mathrm{K}$ are $\mathrm{N} \times \mathrm{N}$ square matrices and $\mathrm{Q}$ and $\mathrm{p}$ are $\mathrm{N}$ vectors. In this study, $\mathrm{n}=5$ or $\mathrm{N}=7$ is used to provide an adequate accuracy for vehicle/guideway systems with various traveling speeds. Therefore, Eq. 39 can be solved by closed. form solution or numerical solution.

The interest is in the steady-state or repetitive condition of guideway deflections and vehicle heave accelerations for one-dimensional vehicles. The steady state exists after a vehicle with a given arbitrary set of initial conditions has traversed a sufficient number of spans in which the vehicle state entering a span is identical to the vehicle state leaving the span or, in fact, entering the next span. For a vehicle starting with zero initial conditions, the number of spans for vehicle crossing to reach a steady-state condition depends on numbers of modes and vehicle traveling speed ratio. The maximum number of spans for vehicle crossing to reach a steady state is less than 100 in accordance with the calculated results.

\subsection{Results and Discussions}

Figure 9 shows the influence of the vehicle to guideway mass ratio $\varepsilon=$ $\left(m_{p}+m_{s}\right) / m L$ on maximum guideway displacement ratio $Y$ and maximum vehicle acceleration ratios $\ddot{Y}_{p}$ and $\ddot{Y}_{s}$ for both primary and secondary suspensions 
as a function of vehicle traveling speed ratio $\mathrm{v} / \mathrm{v}_{\mathrm{c}}$. With other vehicle/guideway parameters fixed, the ratio of total vehicle mass to guideway mass has less effect on the vehicle acceleration, both the location of peaks and magnitudes. The location of maximum acceleration peaks occurs at about $0.5 \mathrm{v} / \mathrm{v}_{\mathrm{c}}$, which is corresponding to the system frequency ratio $\Omega$ and vehicle mass ratio $\gamma_{m}$. However, as the mass ratio decreases, the ratio of maximum guideway displacement (at midspan) ir.sreases. If the mass ratio is small enough, or $\mathrm{v} / \mathrm{v}_{\mathrm{c}}$ is less than 0.4 , the guideway deflection approache; that of uncoupling situation, which is defined as that a motion force $\left(\varepsilon_{p} \ddot{Y}_{p}+\varepsilon_{s} \ddot{Y}_{s}\right)$ is not considered in the right hand side of Eq. 35 and guideway motion $Y$ and $Y$ are not considered in the left hand side of Eq. 33, which indicates that with a small mass vehicle, dynamic motions of vehicle and guideway can be decoupled, the vehicle can be considered as a moving force on the guideway and the guideway deflection is then used as a known displacement input into the suspension.

Figure 10 shows the influence of vehicle mass ratio $\gamma_{m}$ on maximum guideway displacement ratio $Y$ and vehicle acceleration ratios $\ddot{Y}_{p}$ and $\ddot{Y}_{s}$. Obviously, $\gamma_{\mathrm{m}}$ affects the locations and magnitudes of acceleration peaks. As $\gamma_{\mathrm{m}}$ decreases, there are some characteristics to be noted: the peak locations of accelerations move forward with $\mathrm{v} / \mathrm{v}_{\mathrm{c}}$ increasing; its influence on guideway deflection is reduced (for $\gamma_{\mathrm{m}}=0.20$, decoupling of interaction is acceptable when $\mathrm{v} / \mathrm{v}_{\mathrm{c}} \leq 0.35$; for $\gamma_{\mathrm{m}}=0.05$, decoupling of interaction is acceptable when $\mathrm{v} / \mathrm{v}_{\mathrm{c}} \leq 0.5$ ); the maximum deflection approaches the uncoupling situation, while the acceleration magnitudes of primary suspension increase.

Figure 11 gives the influence of vehicle/guideway frequency ratio $\Omega$ on the guideway displacement ratios and vehicle acceleration ratios. As $\Omega$ increases, acceleration magnitudes of both primary and secondary suspensions decrease and maximum guideway deflection approaches that of the uncoupling situation. Figure 12 gives the influence of vehicle frequency ratio $\gamma_{\mathrm{f}}$. With other parameters maintained constant, $\gamma_{\mathrm{f}}$ only affects the magnitude of guideway deflection and vehicle accelerations but not the locations of peaks. 
Figures 13 and 14 show the influence of vehicle damping $\zeta_{p}$ and $\zeta_{\mathrm{s}}$. They both affect the guideway deflection and vehicle acceleration, but $\zeta_{s}$ has more effects on primary acceleration.

In summary, the vehicle/guideway parameters are of particular interest in the analysis of vehicle/guidevay interaction. Decreasing $\varepsilon$ and $\gamma_{m}$ and increasing $\Omega$ and $\gamma_{\mathrm{f}}$ will tend to reduce the dynamic interaction between vehicle and guideway. In general cases, if $\varepsilon \leq 0.25, \gamma_{m} \leq 0.1$ an $i \Omega>3$, when vehicle traveling speed ratio $\mathrm{v} / \mathrm{v}_{\mathrm{c}}$ is less than 0.5 , the vehicle/guideway interactions can be neglected. To reduce the vehicle heave acceleration and obtain a better ride quality, it is wise to increase $\Omega$, decrease $\gamma_{f}$, and increase $\zeta_{s}$ and $\zeta_{p}$.

Figures 15 and 16 show comparison of time histories of the steady-state guideway displacement and vehicle primary and secondary accelerations for different vehicle traveling speed ratios $\left(v / v_{c}=0.25\right.$ in Fig. 15 and $v / v_{c}=0.50$ in Fig. 16) with $\varepsilon=0.5, \gamma_{m}=0.1, \Omega=3, \gamma_{f}=0.25, \zeta_{n}=0.02, \zeta_{p}=0.1$, and $\zeta_{s}=0.25$. With these results, it is noted that dynamic interaction between vehicle and guideway has less influence on the secondary suspension at given parameters; it effects guideway displacement less when $v / v_{c}=0.25$ than that when $v / v_{c}=0.5$, but effects acceleration of primary suspension more when $v / \mathrm{v}_{\mathrm{c}}=0.25$ than that when $\mathrm{v} / \mathrm{v}_{\mathrm{c}}=$ 0.5 .

\section{Conclusions}

The dynamic interactions between vehicle and guideway of maglev system have been investigated in this paper by modeling vehicle as: a concentrated moving force traveling on the guideway, and a two-degree-of-freedom model.

For a moving force on a single-span or two-span beam, the dynamic deflections of simply-supported guideway spans are evaluated for various combinations of constant and pulsating forces moving along the guideway. In 
this case, traveling speeds of the moving force play a very important role in the beam response characteristics. The maximum deflection of the beam and the location of moving force on the beam at which the maximum deflection occurs are functions of traveling speeds. Within a certain range of traveling speeds (in practical applications of maglev, $v / v_{c}$ is most likaly to be less than 0.5 , where $v_{c}$ is the critical speed), the moving force will amplify the beam displacement, so the maximum deflection of the beam with a moving for:e will always be laryer than the static deflection due to a constant force at the midspan. Damping tends to decrease beam response regardless of the traveling speed of moving force. In the case of a two-span beam, the maximum midspun deflection of the firsti span will be less than that of the single-span beam for any traveling speeds of moving force; while the maximum midspan deflection of the second span will be larger than that of the single-span beam when the traveling speed is within the range of 0.65 to $1.4 \mathrm{v}_{\mathrm{C}}$.

The vehicle model with two-degrees-of-freedom consists of two masses, two springs and two dampings, representing primary and secondary susfensions respectively. The vehicle/guideway parameters, such as traveling speed to the critical speed ratio, vehicle to guideway mass and frequency ratios, secondary suspension to primary suspension mass and frequency ratios, and vehicle and guideway dampings, are considered in the analysis of vehicle/guideway interactions within practical interest ranges. The influences of those parameters on the magnitudes of guideway deflections and vehicle accelerations are evaluated, and the results are compared with the situation when vehicle acceleration forces are neglected and only a constant force due to the vehicle weight is applied on the guideway.

The maximum guideway deflection which directly related to the maximum stress and bending moment sustained by the guideway and maximum vehicle accelcrations which related to the ride quality are functions of traveling speed ratio and other vehicle/guideway parameters. The detailed study with those parameters indicates that when the vehicle traveling speed ratio is less than 0.5 , 
and with in some ranges of vehicle/guideway parameters, for example, the vehicle/guideway mass ratio $\varepsilon \leq 0.25$, the vehicle mass ratio $\gamma_{m} \leq 0.1$, the vehicle/g $x$ id way frequency ratio $\Omega>3$, the dynamic interaction between vehiclo and guideway can be neglected. In this situation, the dynamic motion cun be decoupled, and furthermore vehicle mudel can be replaced by a concentrated moving orce traveling on the guideway. For practical maglev system, vehicle travelink; speed ratio is most likely to be less than 0.5 . Therefore, the model of a moving l'orce may be introduced into the dynamic analysis of maglev systems. In this range, the maximum displacement ratio of a two-span guideway is smaller than thut of a single-span guideway. Without mnsidering other factors, a twospan gu dcway appears to be more efficient in achieving better rido quality.

For vehicle design, it is wise to increase vehicle/guideway froquency ratio $\Omega$, increas 3 vehicle suspension dampings $\zeta_{s}$ and $\zeta_{p}$, and dacrease primary to secondary suspension frequency ratio $\gamma_{\mathrm{f}}$ to obtain a better ride quality.

\section{Ackulowledgments}

Thy is work was performed under the sponsorship of the U.S. Army Corps of Engine ers and the Federal Railroad Administration through interagency agreerents with the U.S. Department of Energy. 


\section{References}

1. Chiu, W. S., et al. 1971. "Influence of Vehicle and Distributed Guideway Parameters on High Speed Vehicle-Guideway Dynamic Interaction," Trans. of ASME, J. of Dynamic System, Measurement, and Control, pp. 25-34.

2. Coffey, H. T., Chilton, F., and Foppie, L, O, 1972. "The Feasibility of Magnetically Levitating High Speed Ground Vehicles," Stanford Research Institute, Report Nu. FRA-PB210505.

3. Coffey, H. T., Colton, J. D., and Mahrer, K. D. 1973. "Study of Magnetically Levitateci Vehicle," Stanford Research Institute, Report No. FRA-R'T-73-24, 13221696.

4. Coffey, H. T., Colton, J. D., Solinsky, J. C., and Woodbury, J. R. 1974. "An Evaluation of the Dynamiss of Magnetically Levitated Vehicle," Stanford Research Institute, Report No. FRA-ORD and D-74-41, PB236671/4GA.

5. Fryba, L. 1972. "Vibration of Solids and Structures Under Moving Loads," Noordhoff International Publishing, Groningen, The Netherlands.

6. Johnson, L. R, et al. 1989. "Maglev Vehicles and Superconductor Technology: Integration of High-Speed Ground Transportation Into the Air Travel System." Argonne National Laboratory, ANL/CNSV-67.

7. Katz, R. M. et al. 1974. "Performance of Magnetic Suspenaions for High Speed Vehicles Operating Over Flexible Guideways," Journal of Dynamic Systems, Measurement, and Control, Vol. 96, pp. 204-212.

8. Kerr, A. D. 1981. "Continuously Supported Beams and Plates Subjected to Moving Loads - A Survey," SM Archives, Vol, 6, Issue 4, pp. 401-449. 
9. Philco-Ford Corporation 1975. "Conceptual Design and Analysis of the Tracked Magnetically Levitated Vehicle Technology Program, Repulsion Scheme. Vol. I. Technical Studies." Report DOT-F'T-40024 (Task 1).

10. Richardson, H. H., and Wormley, D. N. 1974. "Transportation Vehicle/Beam-Elevated Guideway Dynamic Interactions: A State-of-the-Art Review," Journal of Dynamic Systems, Measurement, and Control, Vol. 96, pp. 169-179.

11. Sinha, P. K. 1987. "Electromagnetic Suspension, Dynamics and Control." Peter Peregrinus Ltd, London, United Kingdom.

12. Ting, E. C., Genin, J., and Ginsberg, J. H. 1974. "A General Algorithm for Moving Mass Problems," J. of Sound and Vibration, Vol. 33, 49-58.

13. Uher, R. A. 1989. "MAGLEV: An Emerging Transportation Technology to Meet an Imminent Transportation Need." Proc. of the International Conference Maglev '89, July 1989, pp. 115-122.

14. Wilson, J. F. 1973. "Response of Simple Spans to Moving Mass Loads," AIAA Journal, Vol. 11, pp. 4-5.

15. Yadav, D., and Upadhyay, H. C. 1991. "Non-Stationary Dynamics of Train and Flexible Track Over Inertial Foundation During Variable Velocity Runs," J. of Sound and Vibration, Vol. 147, No. 1, pp. 57-71.

16. Zicha, J. H. 1986. "Civil Aspects of Mag? zv Design." International Conference on Maglev and Linear Drives, Publication IEEE 86CH2276, pp. 69-87. 


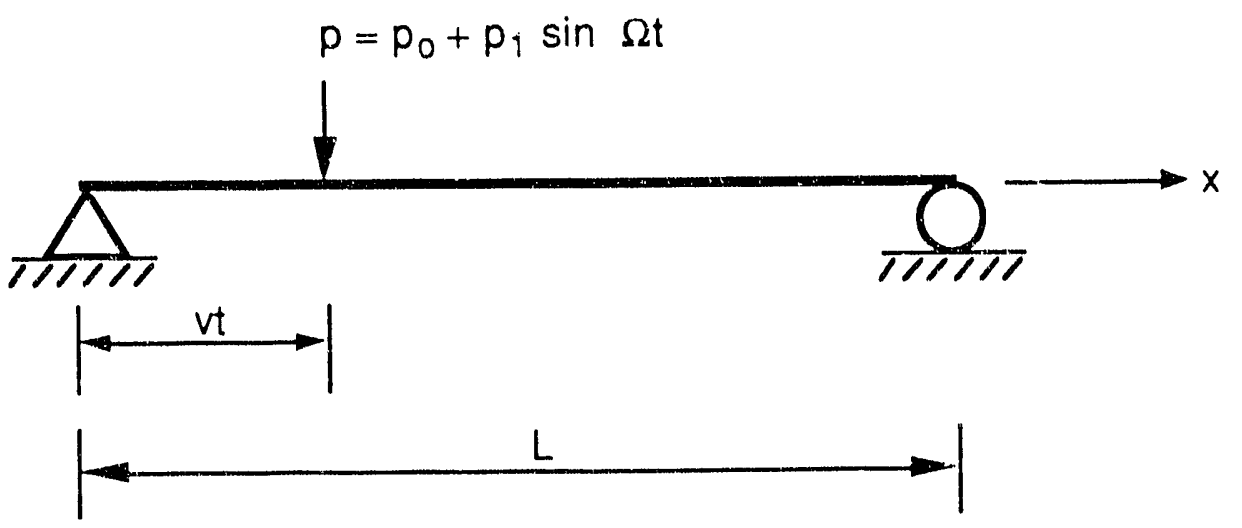

Fig. 1. A simply-supported beam subjected to a moving force $p$ 

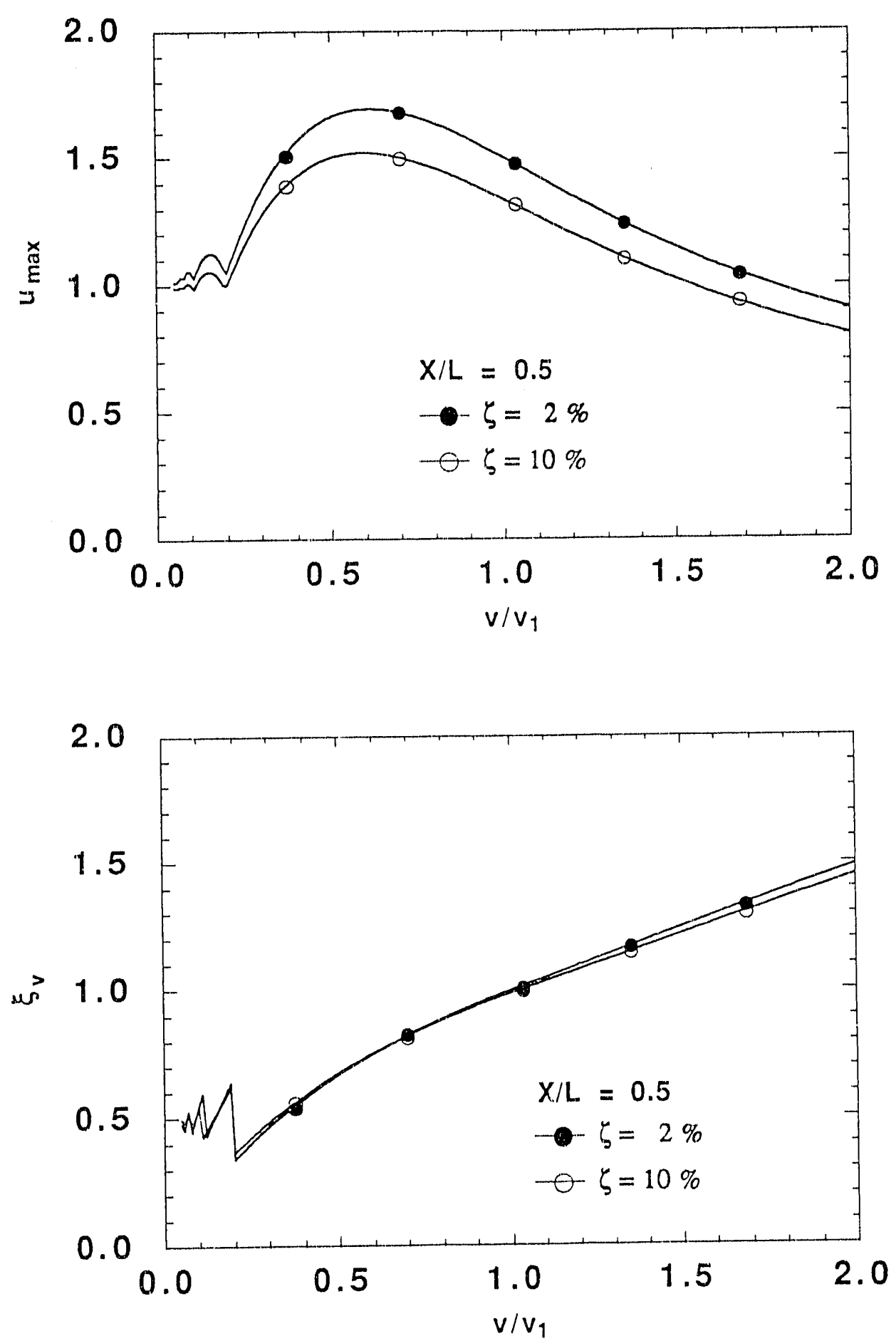

Fig. 2. Maximum displacement ratio and force location of occurrence as a function of speed ratio for a single-span beam 

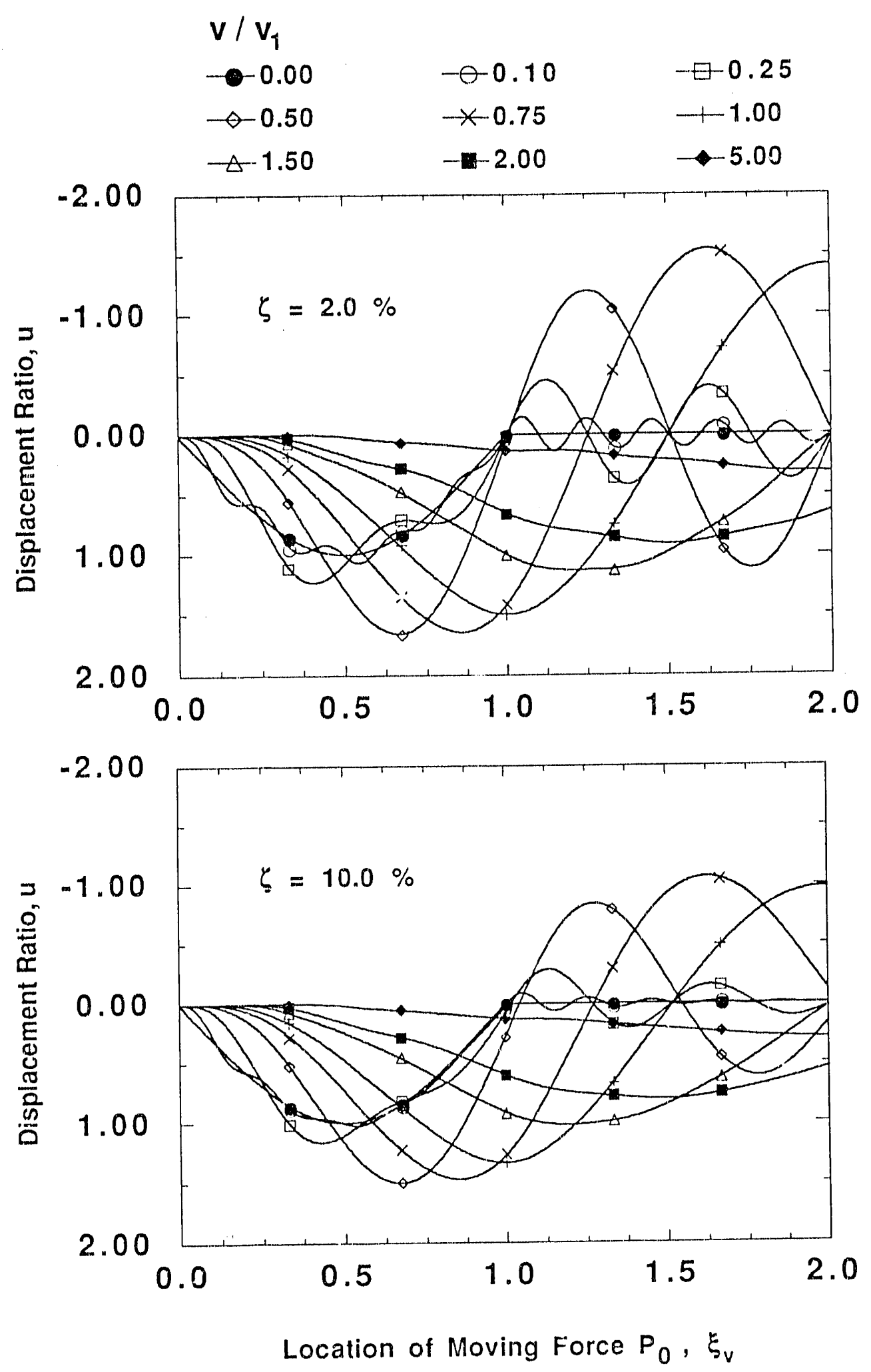

Fig. 3. Displacement ratio as a function of the location of the moving force with different values of $\mathrm{v} / \mathrm{v}_{1}$ for a single-span beam 

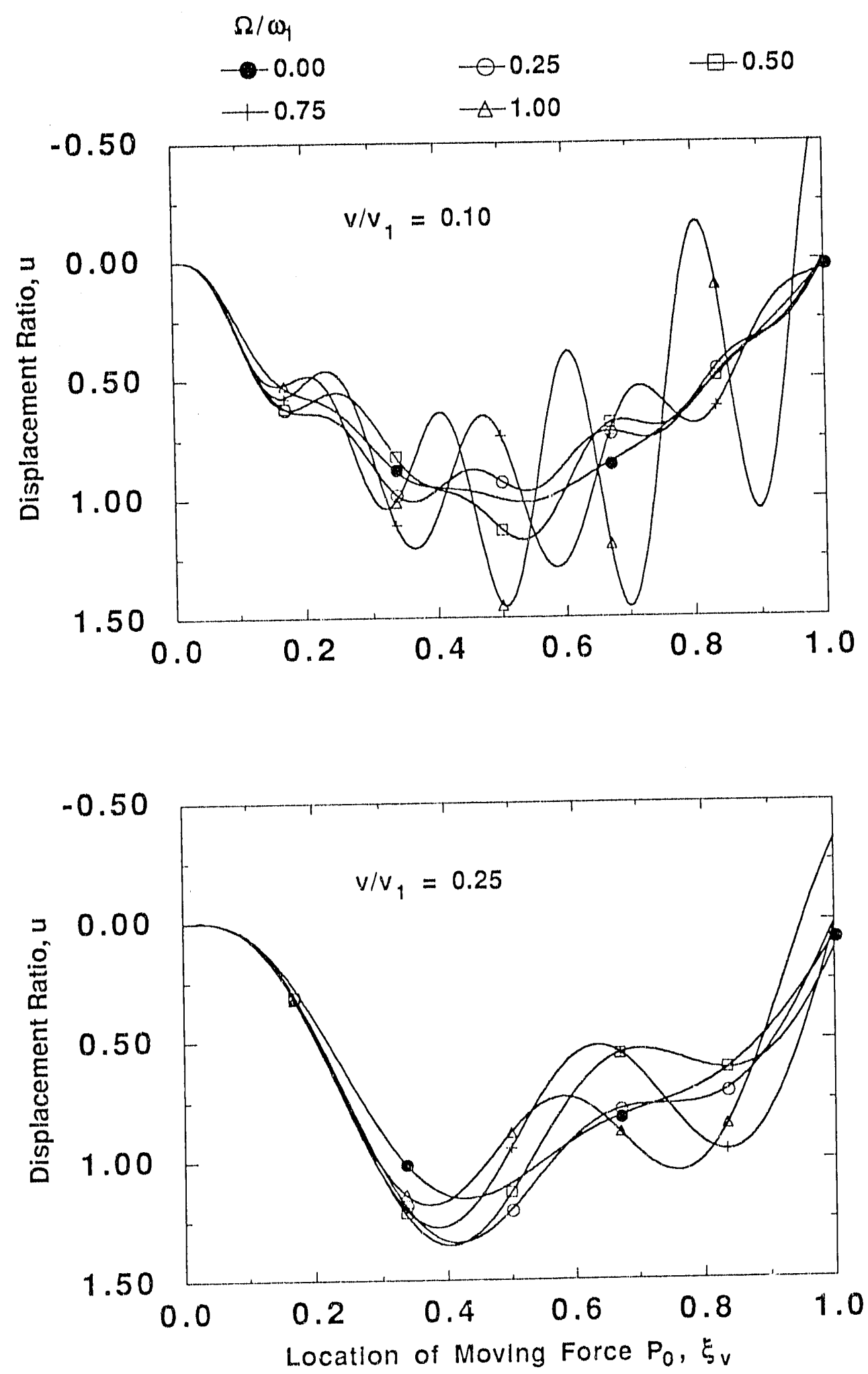

Fig. 4. Displacement ratio as a function of the lucation of the moving force with different values of $\Omega / \omega_{1}$ and $\zeta_{n}=2 \%, p_{1} / p_{0}=0.1$ for a single-span beam with different values of $\Omega / \omega_{1}$ 


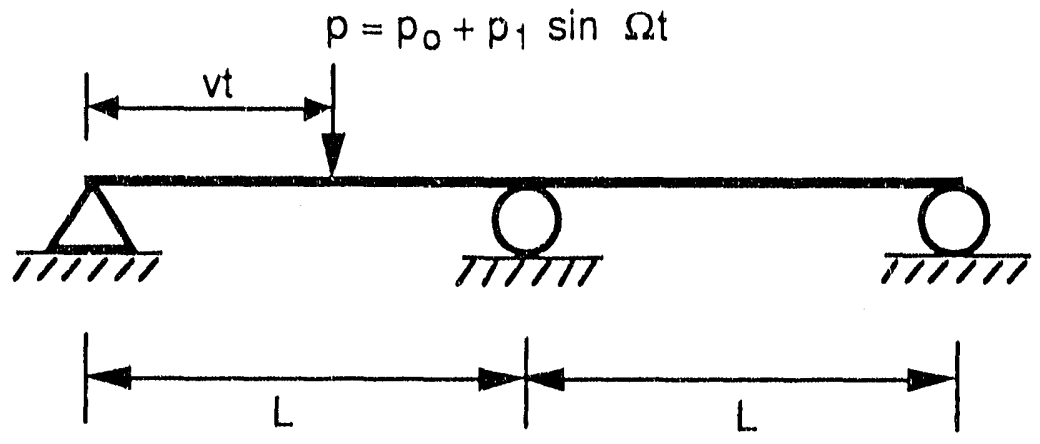

Fig. 5. A two-span beam subjected to a moving force $p$ 

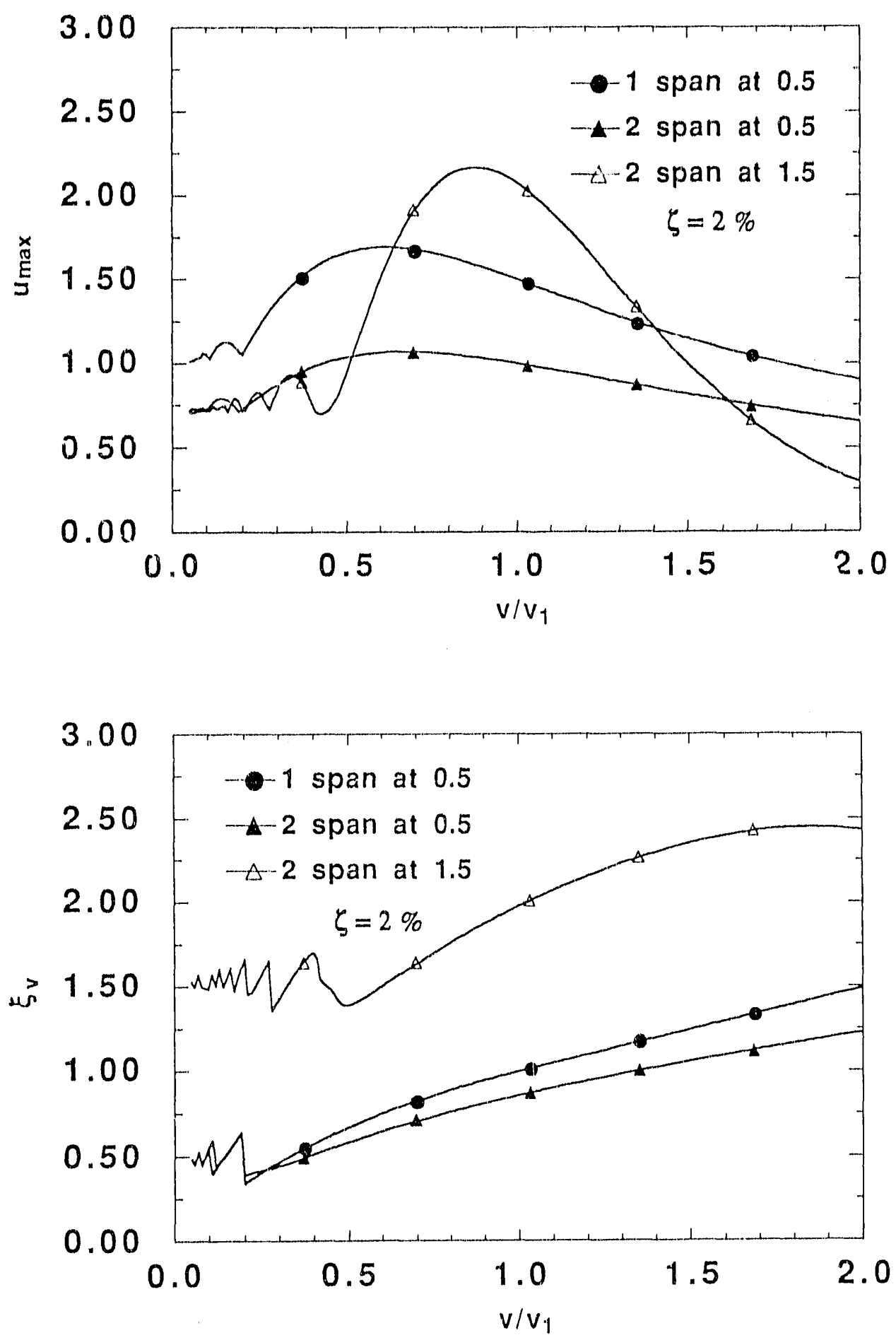

Fig. 6. Maximum displacement ratio at midspan and force location of occurrence as a function of speed ratio 

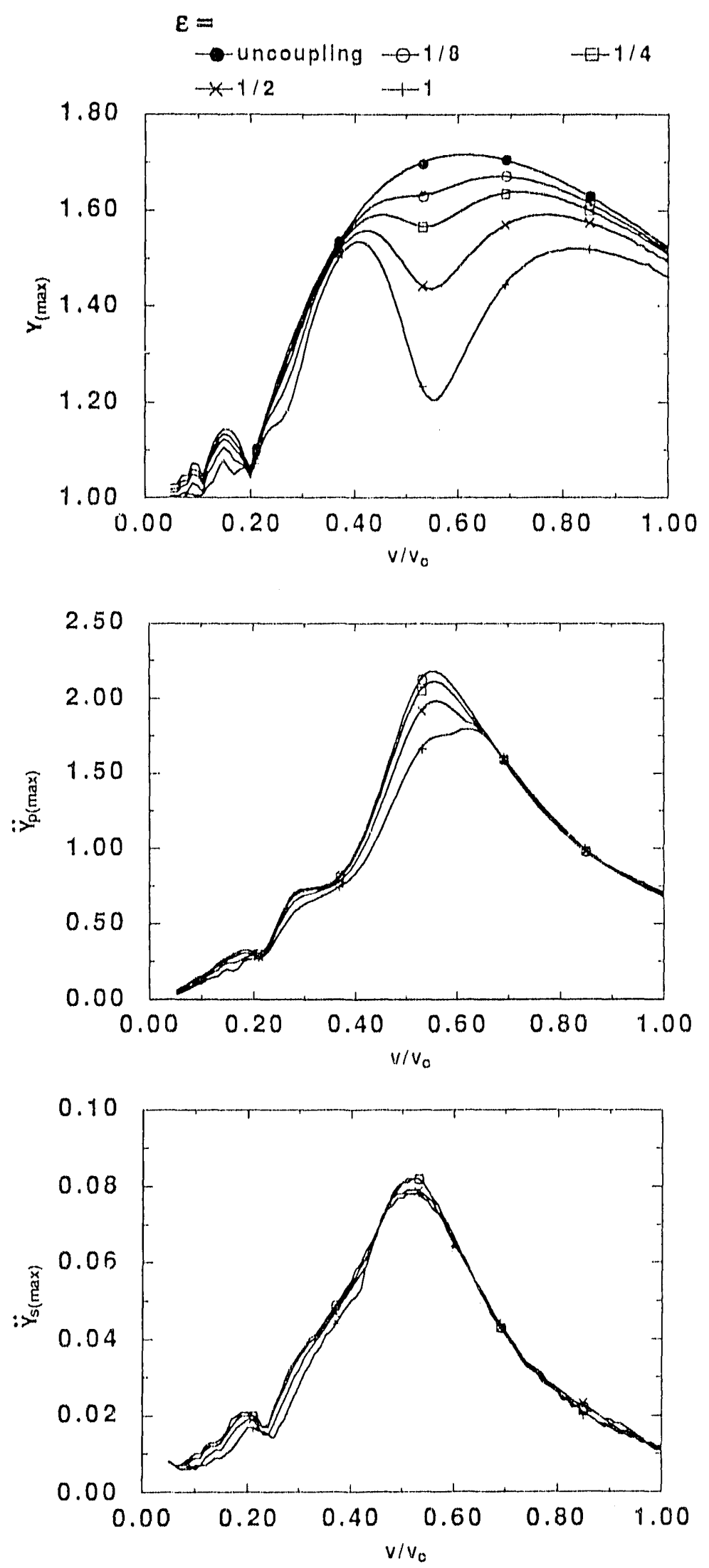

Fig. 9. Influence of mass ratio of vehicle to guideway upon the maximum guideway displacement and vehicle accelerations with system parameters $\gamma_{m}=0.1, \Omega=3, \gamma_{\mathrm{f}}=0.25, \zeta_{\mathrm{n}}=2 \%, \zeta_{\mathrm{p}}=10 \%, \zeta_{\mathrm{s}}=25 \%$ 

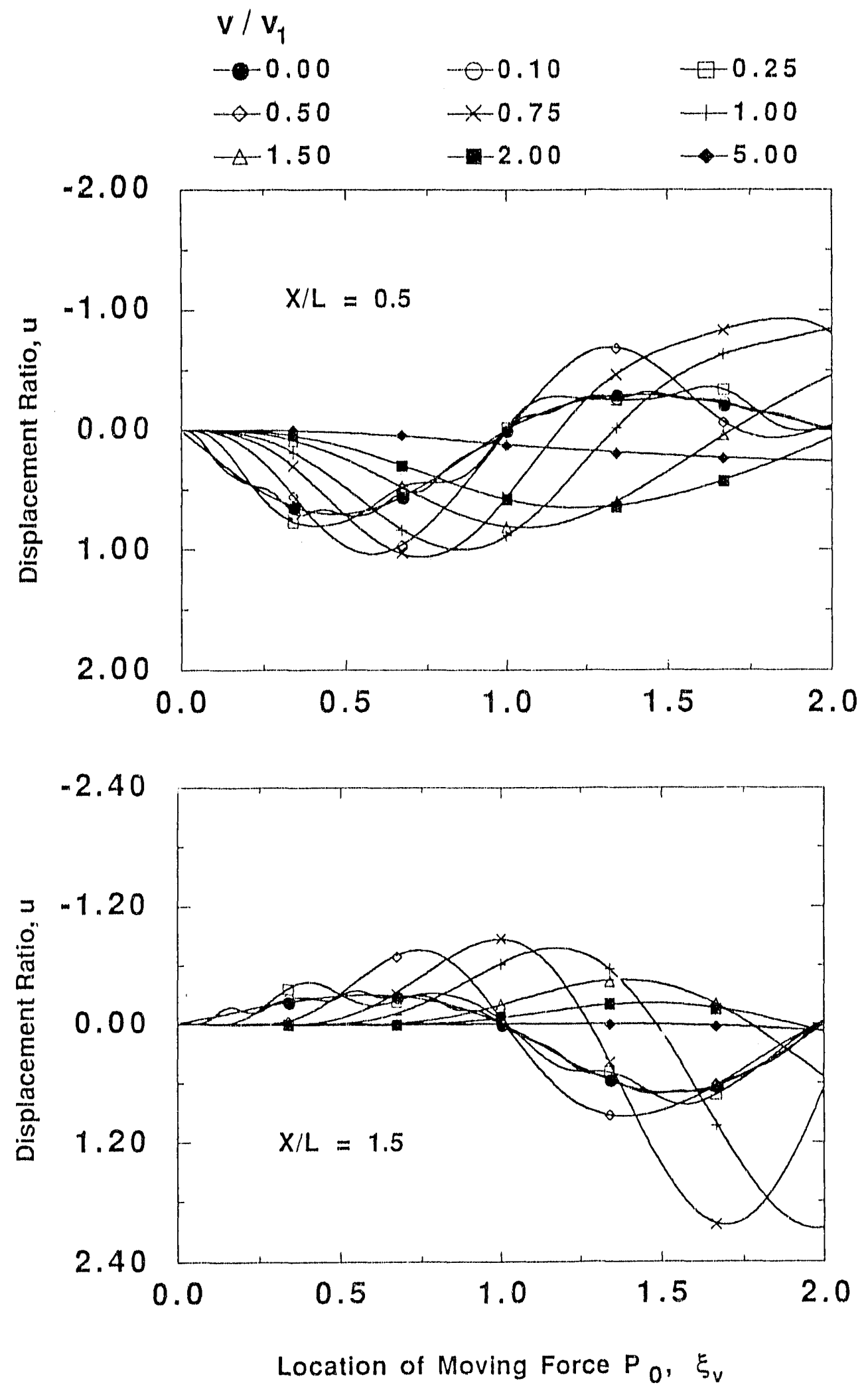

Fig. 7. Displacement ratio as a function of the location of the moving force for different values of $v / v_{1}$ for a two-span beam 


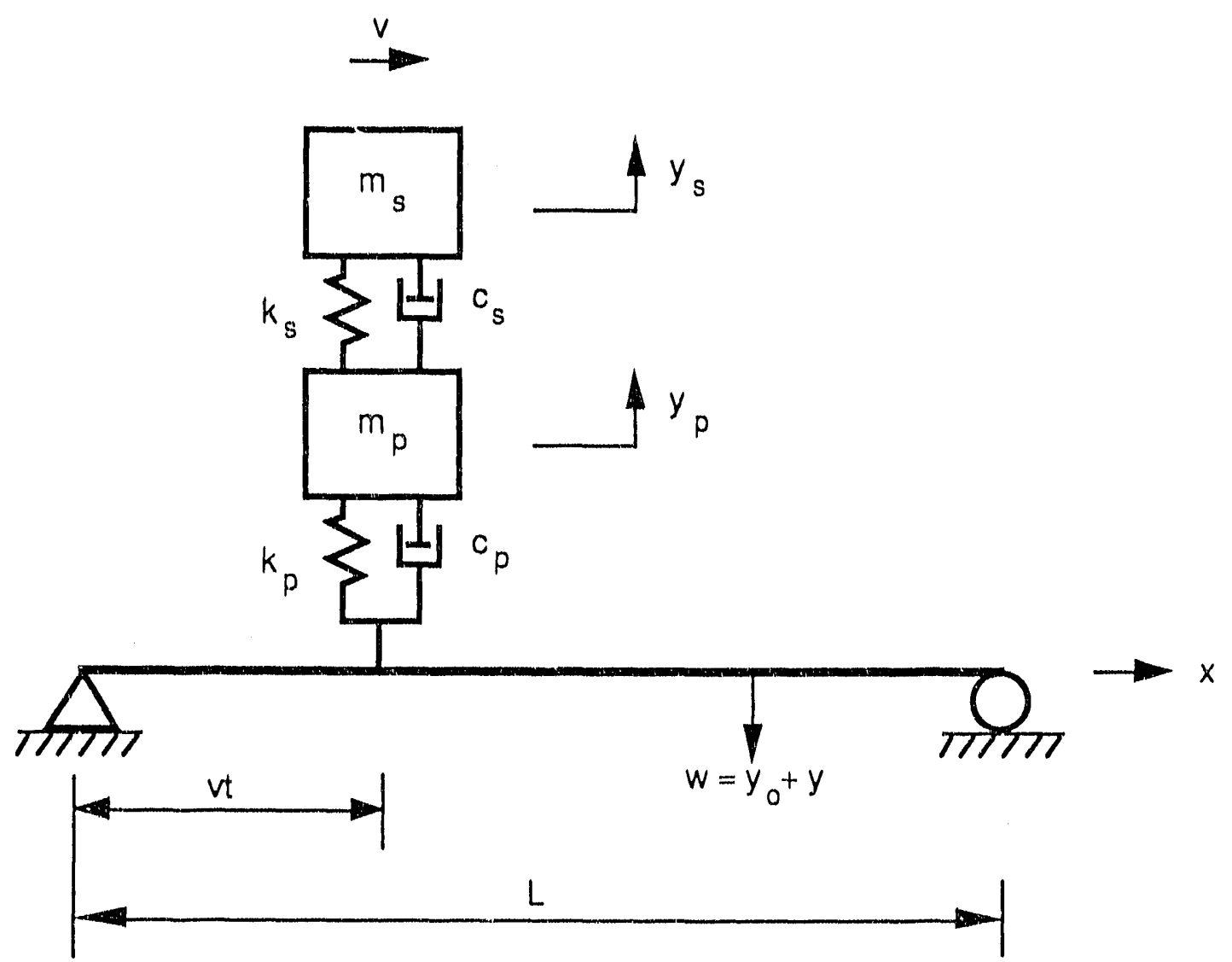

Fig. 8. A two-degree-of-freedom vehicle traveling on a simply-supported guideway 

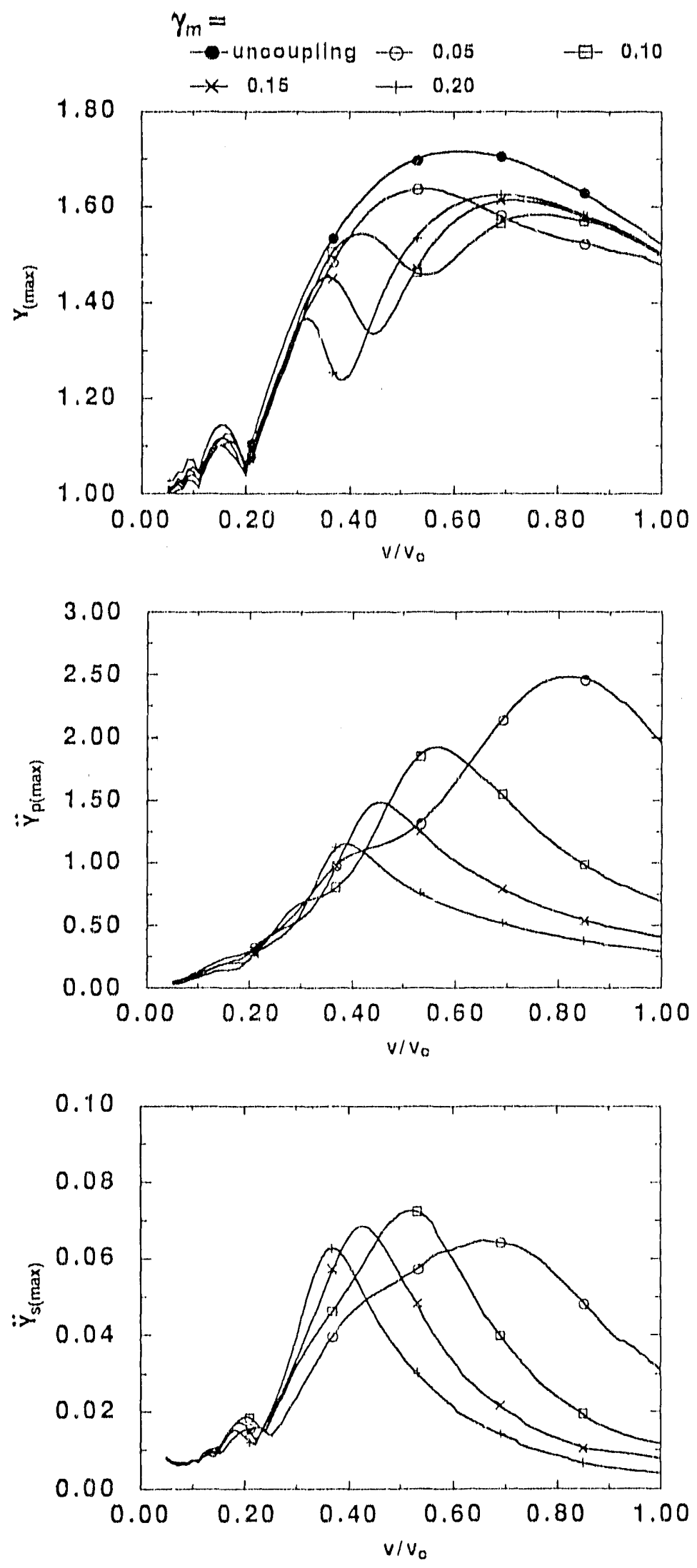

Fig. 10. Influence of mass ratio of primary to secondary suspensions upon the maximum guideway displacement and vehicle accelerations with system parameters $\varepsilon=0.5, \Omega=3, \gamma_{\mathrm{f}}=0.25, \zeta_{\mathrm{n}}=2 \%, \zeta_{\mathrm{p}}=10 \%, \zeta_{\mathrm{s}}=25 \%$ 

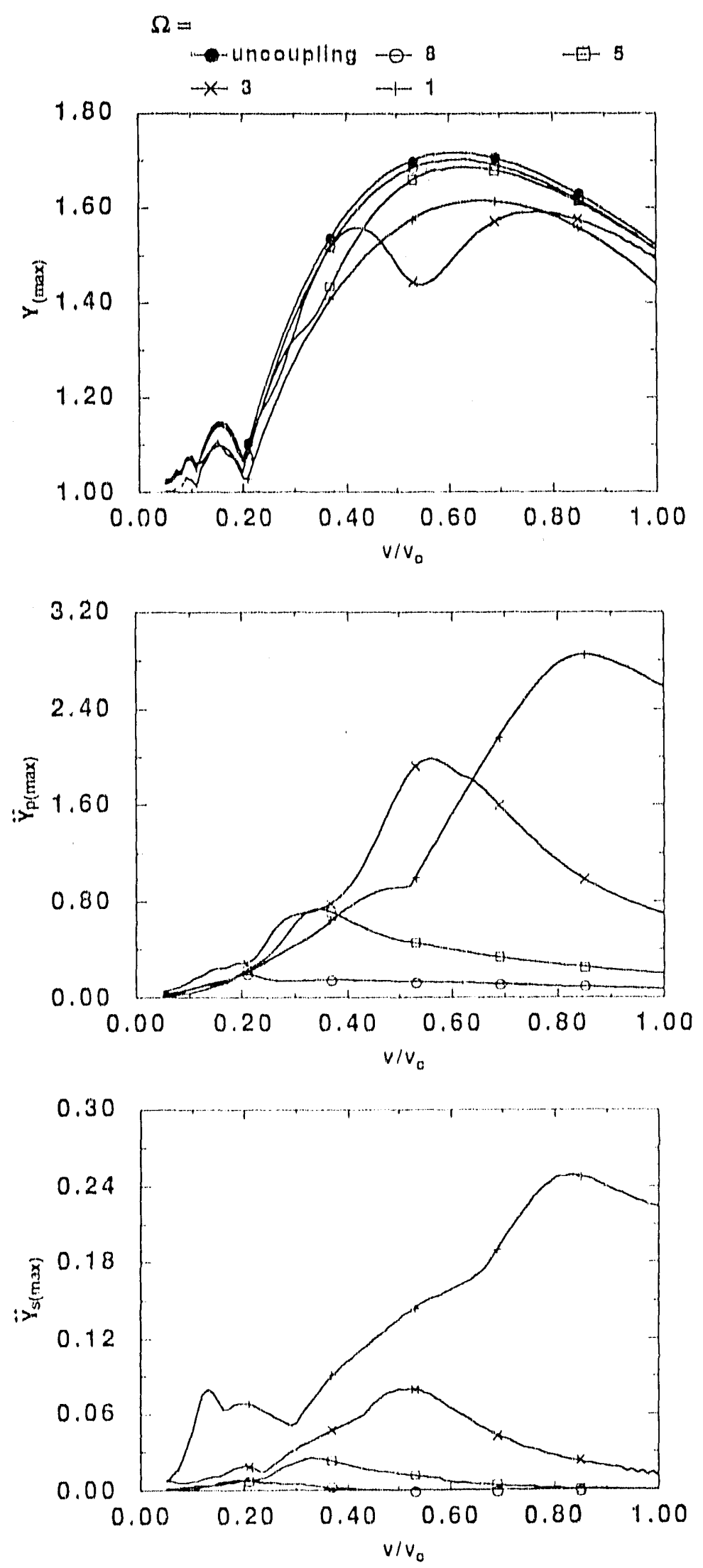

Fig. 11. Influence of frequency ratio of guideway to vehicle upon the maximum guideway displacement and vehicle accelerations with system parameters $\varepsilon=0.5, \gamma_{m}=0.1, \gamma_{f}=0.25, \zeta_{n}=2 \%, \zeta_{p}=10 \%, \zeta_{s}=25 \%$ 

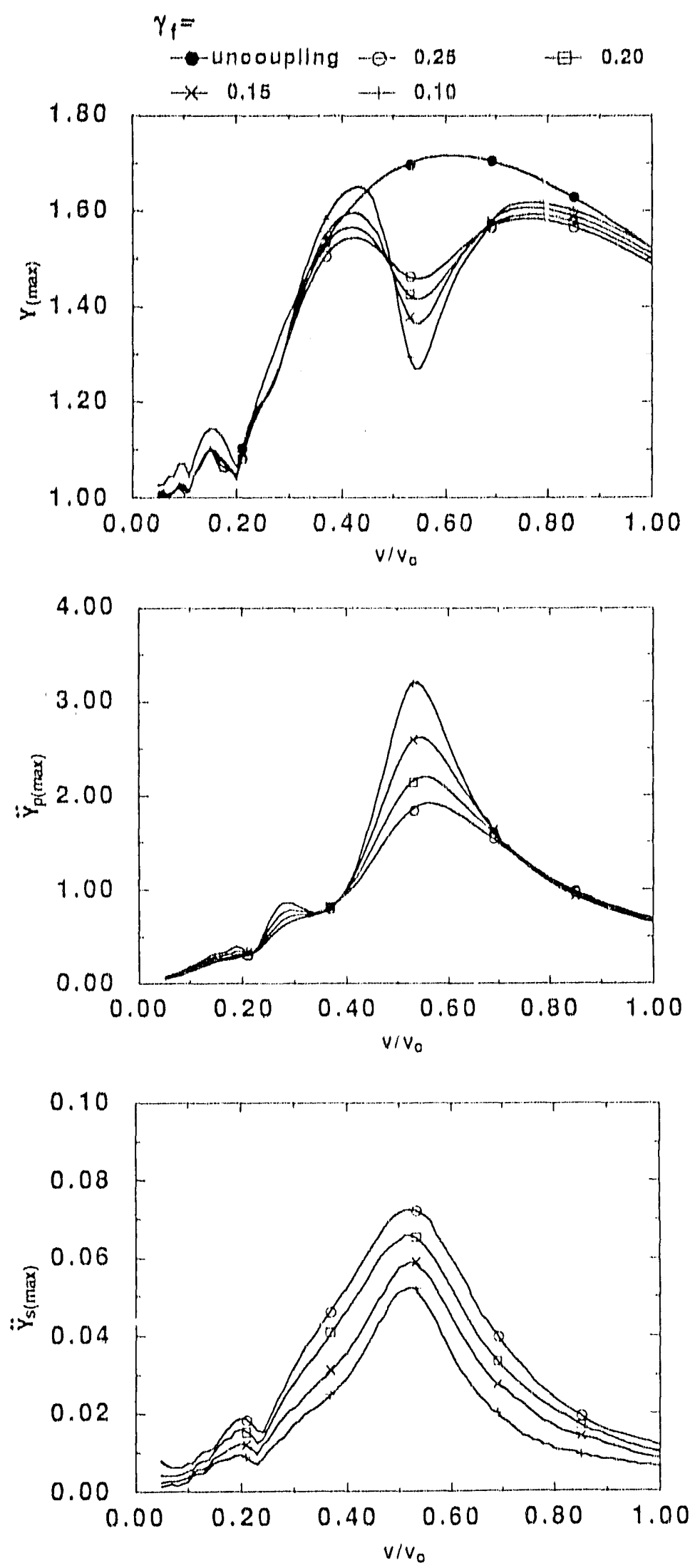

Fig. 12. Influence of frequency ratio of secondary to primary suspension upon the maximum guideway displacement and vehicle accelerations with system parameters $\varepsilon=0.5, \gamma_{m}=0.1, \Omega=3, \zeta_{n}=2 \%, \zeta_{p}=10 \%, \zeta_{s}=25 \%$ 

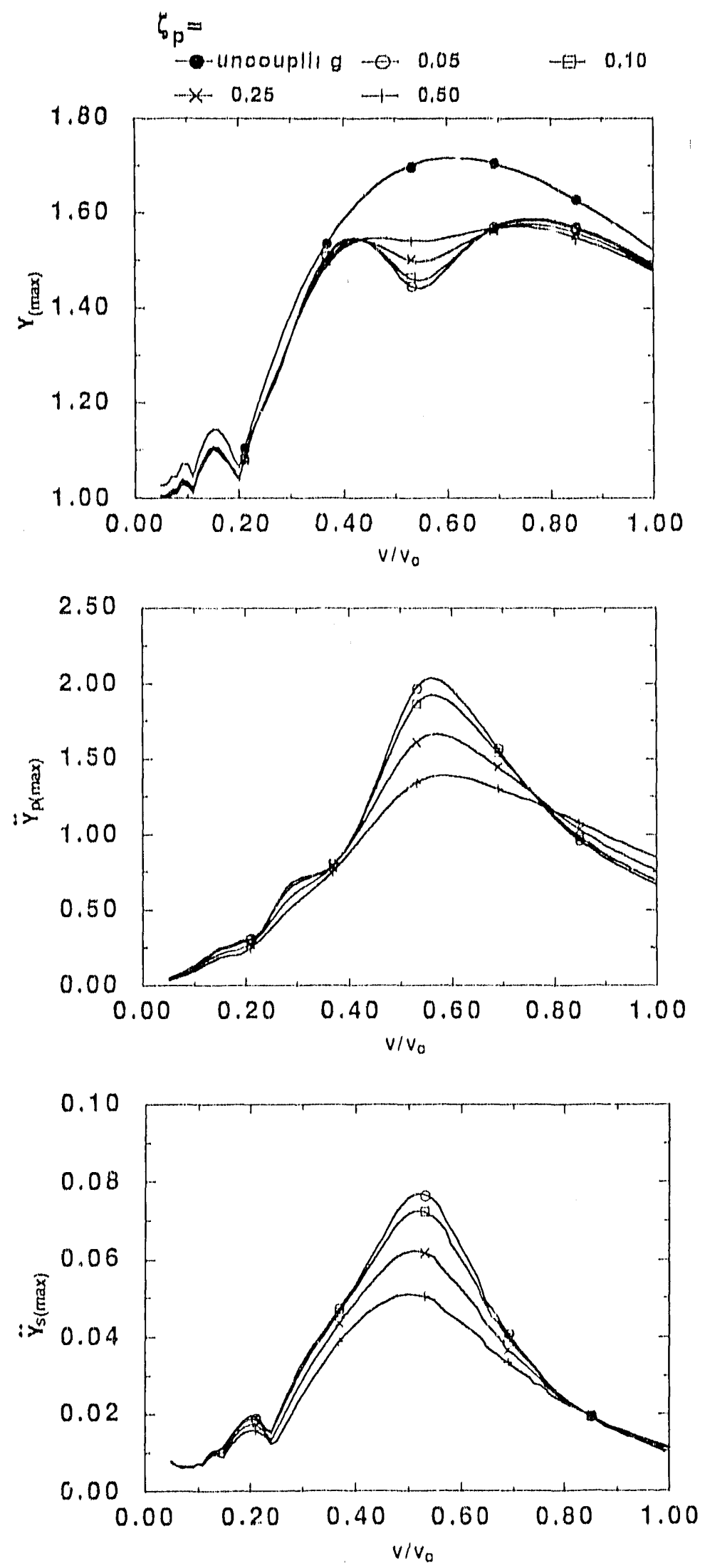

Fig. 13. Influence of damping ratio of primary suspension upon the maximum guideway displacement and vehicle accelerations with system parameters $\varepsilon=0.5, \gamma_{\mathrm{m}}=0.1, \Omega=3, \gamma_{\mathrm{f}}=0.25, \zeta_{\mathrm{n}}=2 \%, \zeta_{\mathrm{s}}=25 \%$ 

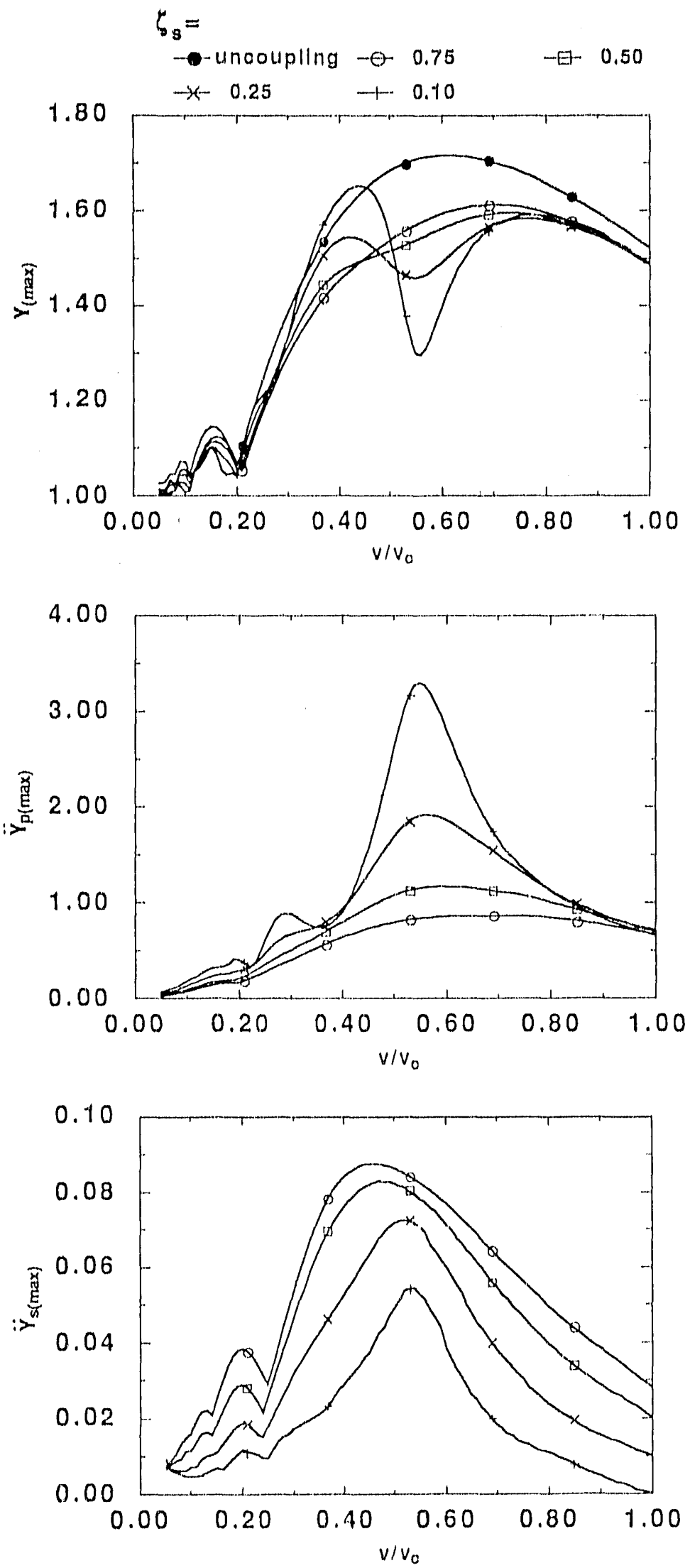

Fig. 14. Influence of damping ratio of secondary suspension upon the mnximum guideway displacement and vehicle accelerations with system parameters $\varepsilon=0.5, \gamma_{m}=0.1, \Omega=3, \gamma_{f}=0.25, \zeta_{n}=2 \%, \zeta_{p}=10 \%$ 

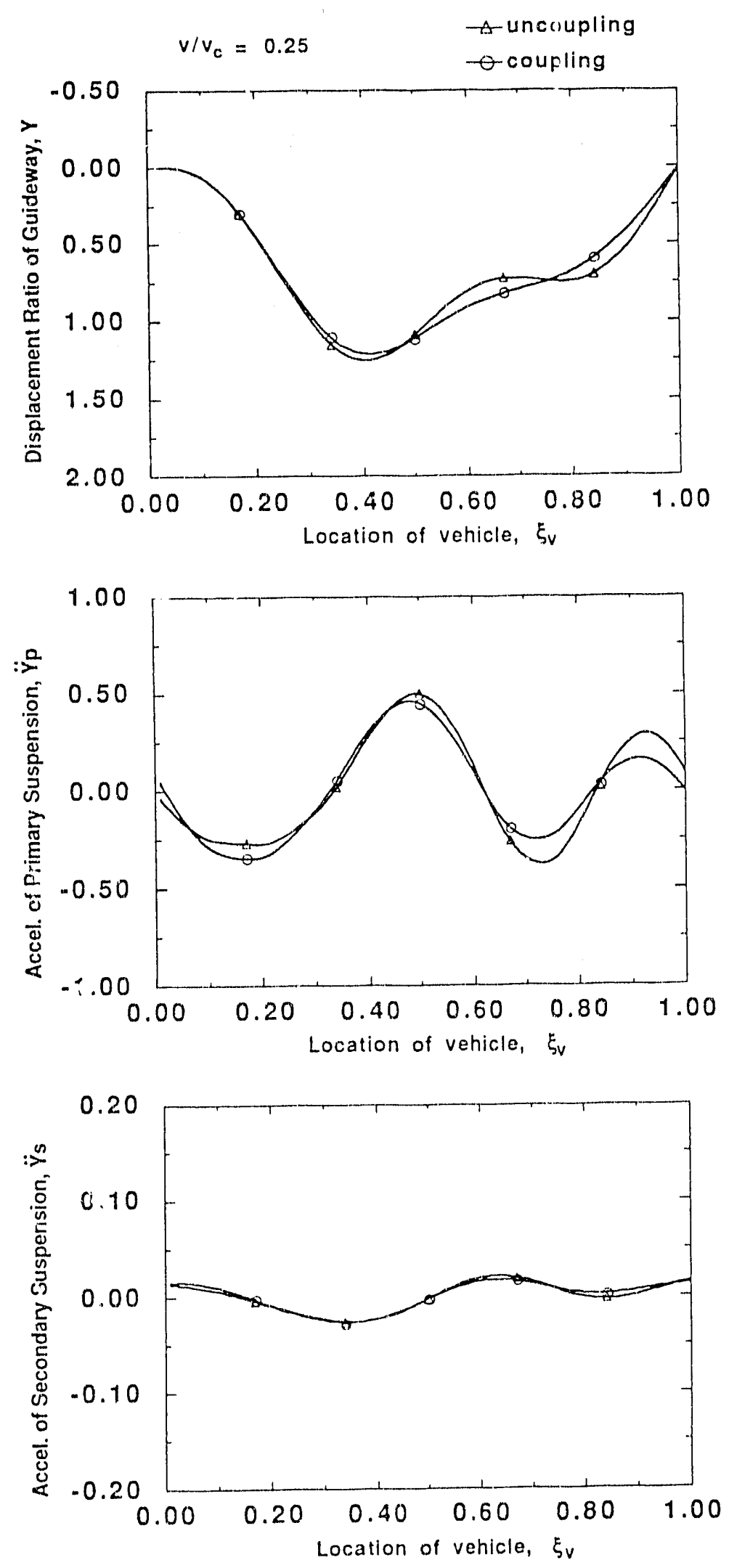

Fig. 15. Time histories of the steady-state guideway displacement ratio and vehicle accelerations with speed ratio $\mathrm{v} / \mathrm{v}_{\mathrm{c}}=0.25$ and system parameters $\varepsilon=0.5, \gamma_{m}=0.1, \Omega=3, \gamma_{f}=0.25, \zeta_{n}=2 \%, \zeta_{p}=10 \%, \zeta_{s}=25 \%$ 

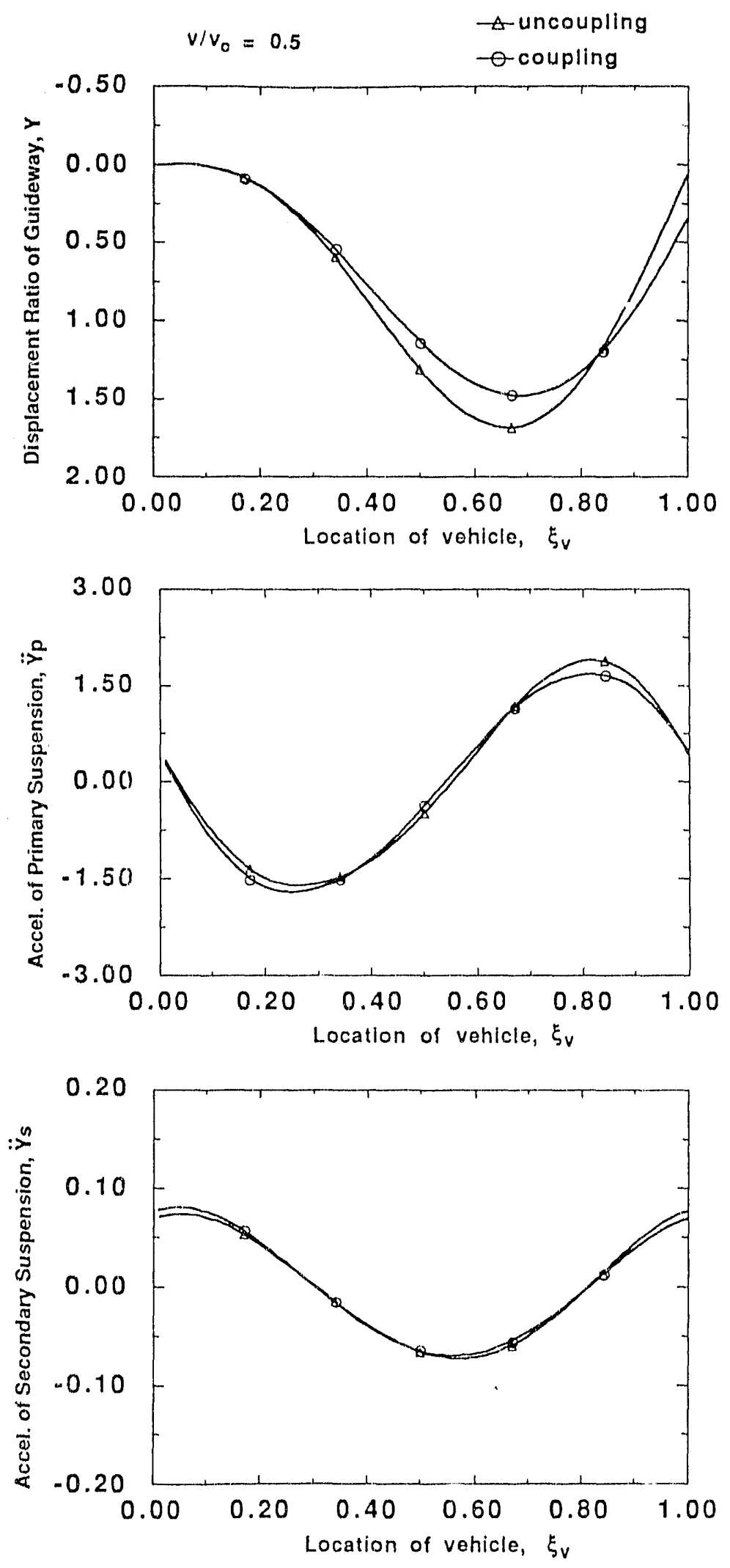

Fig. 16. Time histories of the steady-state guideway displacement ratio and vehicle accelerations with speed ratio $\mathrm{v} / \mathrm{v}_{\mathrm{c}}=0.5$ and system parameters $\varepsilon=0.5, \gamma_{m}=0.1, \Omega=3, \gamma_{f}=0.25, \zeta_{n}=2 \%, \zeta_{p}=10 \%, \zeta_{s}=25 \%$ 


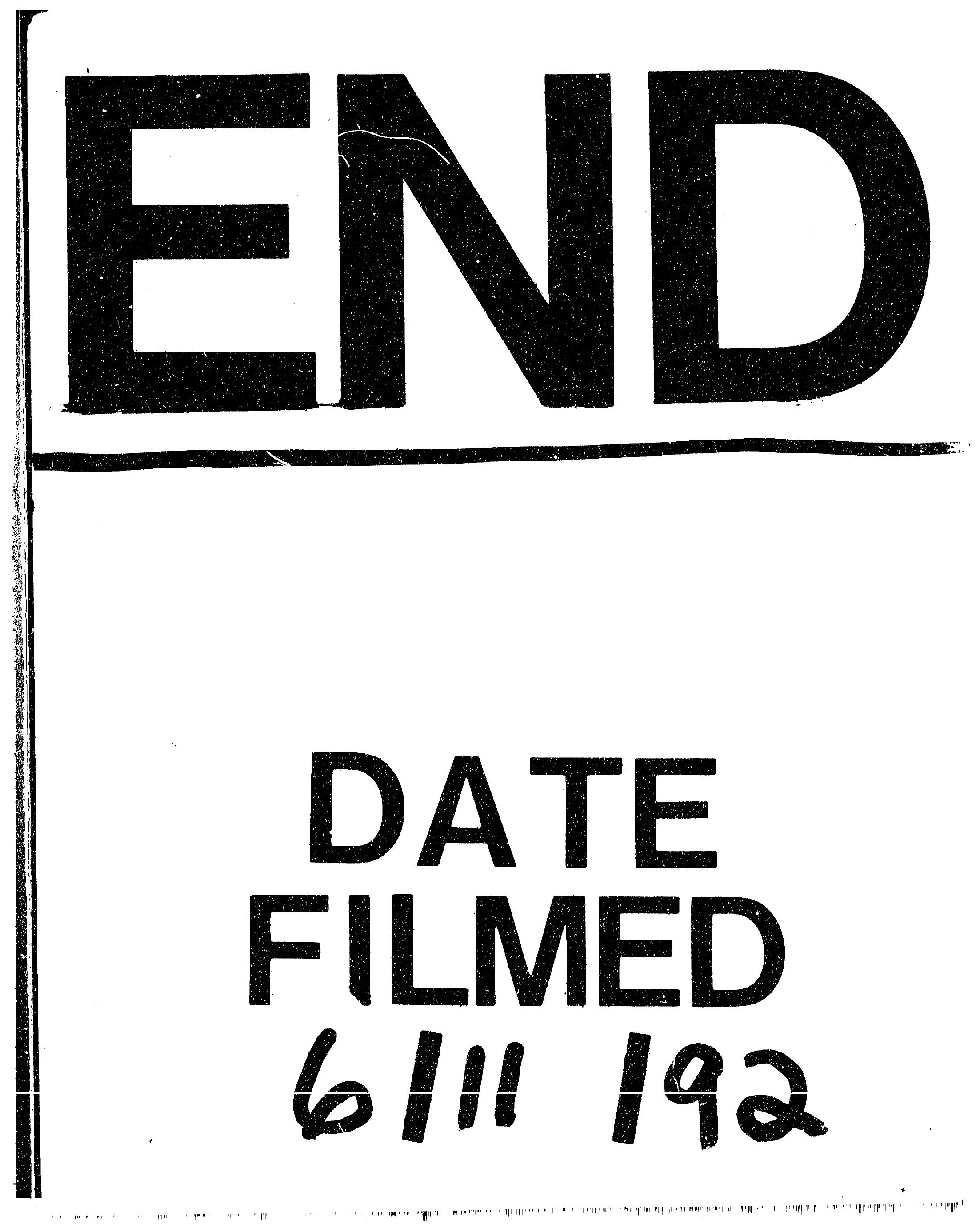


